DOI: $10.24850 / \mathrm{j}-$ tyca-2021-05-02

Articles

\title{
Velocity scaling in open-channel flows with sediment transport
}

\section{Escala de velocidad en canales abiertos con transporte de sedimentos}

Pietro Corapi ${ }^{1}$, ORCID: https://orcid.org/0000-0001-8626-0134

Ximena Carolina Acaro Chacón², ORCID: https://orcid.org/0000-00017092-7248

Luis Enrique Chuquimarca Jimenez 3 , ORCID: https://orcid.org/00000003-3296-4309

1Universidad de Guayaquil, Guayaquil, Ecuador, pietro_corapi@ug.edu.ec 2Universidad de Guayaquil, Guayaquil, Ecuador, ximena.acaroc@ug.edu.ec

3Universidad Estatal Península de Santa Elena, La Libertad, Ecuador, Ichuquimarca@upse.edu.ec 


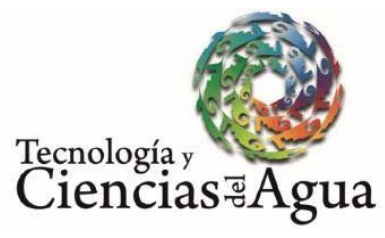

2021, Instituto Mexicano de Tecnología del Agua

Open Access bajo la licencia CC BY-NC-SA 4.0

(https://creativecommons.org/licenses/by-nc-sa/4.0/)

Corresponding author: Pietro Corapi, pietro_corapi@ug.edu.ec

\begin{abstract}
Under uniform and non-uniform flow conditions, the most employed velocity scale in OCFs is the shear velocity. In non-uniform flow conditions with sediment transport, the log-law velocity distribution could be absent, so it is not possible to apply the conventional methods to compute the shear velocity. This work aims to define a way to compute the best value of velocity scale in non-uniform flows with different sediment transport under the absence of the log-law velocity distribution. Laboratory tests were performed by using a PIV system to measure the time and space velocity vectors, the total shear stress profiles were computed through the momentum balance analysis and the co-spectrum of the velocity fluctuation to define different values of the velocity scale factor. To determine which of the different values gives the better scaling of the velocity profiles, a comparison of the non-dimensional velocity profiles was done by showing that the value at the crest level from a linear regression of the shear stress profile, obtained with the momentum balance analysis, is the best velocity scale value.
\end{abstract}

Keywords: Velocity scale, non-uniform flow, open channel flow, PIV, sediment transport, velocity profiles, shear stress. 


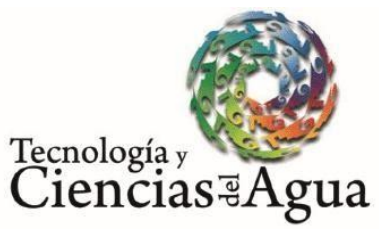

2021, Instituto Mexicano de Tecnología del Agua

Open Access bajo la licencia CC BY-NC-SA 4.0

(https://creativecommons.org/licenses/by-nc-sa/4.0/)

\section{Resumen}

En condiciones de flujo uniforme y no uniforme, la escala de velocidad más empleada en canales abiertos es la velocidad de fricción. En condiciones de flujo no uniforme con transporte de sedimentos, la distribución de velocidad de la ley logarítmica podría estar ausente, por lo que no es posible aplicar métodos convencionales para calcular la velocidad de fricción. El objetivo de este trabajo es definirun método para calcular la escala de velocidad en flujos no uniformes con diferentes condiciones de transporte de sedimentos en ausencia de la distribución de velocidad de la ley logarítmica. Las pruebas de laboratorio se realizaron utilizando un sistema PIV para medir los vectores de velocidad en tiempo y espacio, los perfiles de esfuerzo cortante total se calcularon a través del análisis de equilibrio de momento, y el coespectro de la fluctuación de velocidad para definir diferentes valores del factor de escala de velocidad. Para definir cuál de los diferentes valores proporciona la mejor escala de los perfiles de velocidad se hizo una comparación de los perfiles de velocidad adimensionales. Esta comparación muestra que el valor del esfuerzo cortante al nivel de las crestas del fondo móvil -obtenido a través de una regresión lineal del perfil de esfuerzo cortante calculado a partir del análisis de equilibrio de momento - es el mejor valor de escala de velocidad. 
Palabras clave: escala de velocidad, flujo no uniforme, flujo en canales abiertos, PIV, transporte de sedimentos, perfiles de velocidad, perfiles de velocidad, esfuerzo cortante.

Received: $14 / 02 / 2020$

Accepted: 15/09/2020

\section{Introduction}

The aim of this work is focused on the velocity scaling in Open-Channel Flows (OCFs) over a live bed. The scaling problem has excited great interest in the scientific community for years. Several authors worked on the definition of the scaling parameters. In particular, Zagni (1976) performed a comparative analysis between flow statistics measured over rough impermeable and rough permeable walls characterized by the same surface roughness texture and Pokrajac (2006) studied which is the appropriate velocity scale for scaling turbulent flow quantities across the 


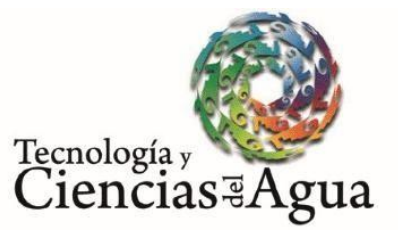

2021, Instituto Mexicano de Tecnología del Agua

Open Access bajo la licencia CC BY-NC-SA 4.0

(https://creativecommons.org/licenses/by-nc-sa/4.0/)

whole flow profile. The velocity scaling has a significant interest, as in solid transport conditions, there is a continuous interaction between the forces that allow sediment motion and the resistance that sediments offer. Particularly in this work, we will see the importance of the correct definition of shear stress that allows the scaling of the results, which have different flow conditions related to various experiments. Furthermore, the knowledge of characteristic shear stress will lead to the definition of the so-called shear velocity that is universally recognized as the velocity scale.

In the proximity of a rough-bed, the temporal averaged flow can become highly spatially heterogeneous making the application of the conventional Reynolds-averaged Navier-Stokes (RANS) equations problematic (Nikora, 2001). If the details of the heterogeneity can be omitted and only the effects at larger scales are relevant, spatially averaging the RANS equations results in a conceptually sound way of upscaling the problem. The upscaled equations to describe turbulent flow over a rough-bed are called the double-averaged (in time and space) Navier-Stokes (DANS) equations.

Exploit the time-space decomposition for instantaneous velocity introduced by Whitaker (1967), in addition to the primary decompositions $u_{j}=\bar{u}+u^{\prime}$ in time or $u_{j}=\left\langle u_{j}\right\rangle+\tilde{\tilde{u}}$ in space, there are subsequent secondary decompositions, $\bar{u}=\left\langle\overline{u_{j}}\right\rangle+\langle\tilde{u}\rangle, u^{\prime}=\left\langle u_{j}^{\prime}\right\rangle+\widetilde{u_{j}^{\prime}}$ (time/space) or $\left\langle u_{j}\right\rangle=\overline{\left\langle u_{j}\right\rangle}+$ $\left\langle u_{j}\right\rangle^{\prime}, \widetilde{u}_{J}=\overline{\widetilde{u}}_{J}+\widetilde{u_{j}^{\prime}}$ (space/time). Owing to the commuting properties of the 
averaging and deviation operators both time/space and space/time decompositions produce identical components (Pokrajac, 2008):

$u_{j}=\left\langle\overline{u_{j}}\right\rangle+\langle\tilde{u}\rangle+\left\langle u_{j}\right\rangle^{\prime}+\widetilde{u_{\jmath}^{\prime}} j=1,2,3$

Where $\langle\bar{u}\rangle$ is the double-averaged velocity in the direction of $x ;\langle\tilde{u}\rangle$ is the spatial perturbation in time-averaged velocity; $\left\langle u_{j}\right\rangle^{\prime}$ is the spatially averaged velocity fluctuation, and $\widetilde{u_{\jmath}^{\prime}}$ is the spatial disturbance in velocity fluctuation. Applying the double-decomposition suggested by Whitaker (1967) to the Navier-Stokes equation, Nikora (2001) proposed the following formulation of the DANS equation.

For the flow region above the crests of roughness elements, $z>z_{c}$ :

$\frac{\partial\left\langle\overline{u_{l}}\right\rangle}{\partial t}+\left\langle\overline{u_{l}}\right\rangle \frac{\partial\left\langle\overline{u_{J}}\right\rangle}{\partial x_{i}}=g_{i}-\frac{1}{\rho} \frac{\partial\langle\bar{p}\rangle}{\partial x_{i}}-\frac{\partial \overline{\left.u_{l}^{\prime} u_{J}^{\prime}\right\rangle}}{\partial x_{j}}-\frac{\partial\left\langle\widetilde{u}_{l} \widetilde{u}_{J}\right\rangle}{\partial x_{j}}+v \frac{\partial^{2}\left\langle\overline{u_{l}}\right\rangle}{\partial x_{j}^{2}}$

These terms are form-induced stresses, form drag, and viscous drag on the bed. The form-induced stresses $\left\langle\tilde{u}_{\imath} \tilde{u}_{\jmath}\right\rangle$ appear as a result of spatial averaging, as the turbulent stresses $\left\langle\overline{u_{\imath}^{\prime} u_{\jmath}^{\prime}}\right\rangle$ appear in the Reynolds equation as a result of the time-averaging process. Namely, $\left\langle\widetilde{u}_{\imath} \widetilde{u}_{\jmath}\right\rangle$ are due to spatial disturbances in the time-averaged flow. To identify $\left\langle\widetilde{u_{\imath}} \widetilde{u_{\jmath}}\right\rangle$, Wilson (1977) 
used the term "dispersive stresses", while Giménez-Curto (1996) prefers the term "form-induced stresses", the latter definition will be used hereinafter.

In general, it is possible to write the DA total shear stress equation as:

$\langle\bar{\tau}\rangle=-\rho\left\langle\tilde{u}_{\imath} \tilde{u}_{j}\right\rangle-\rho\left\langle u_{i}^{\prime} u_{j}^{\prime}\right\rangle+\rho v \frac{\partial u_{i}}{\partial x_{j}}=\left\langle\bar{\tau}_{f}\right\rangle+\left\langle\bar{\tau}_{x y}\right\rangle+\left\langle\bar{\tau}_{v}\right\rangle$

where the stress component $\rho\left\langle\widetilde{u_{\imath}} \widetilde{u_{j}}\right\rangle$ is called form-induced shear stress $\left\langle\bar{\tau}_{f}\right\rangle, \rho\left\langle u_{i}^{\prime} u_{j}^{\prime}\right\rangle$ are called Reynolds Stresses or Turbulent Stresses $\left\langle\bar{\tau}_{x y}\right\rangle$ and $\rho v \frac{\partial u_{i}}{\partial x_{j}}$ viscous shear stress $\left\langle\bar{\tau}_{v}\right\rangle$. Shear stress from co-spectrum of the velocity fluctuation turbulence research is traditionally focused on the mechanisms responsible for Reynolds shear stress, it is the $z$-derivative of $\left\langle\overline{u^{\prime} w^{\prime}}\right\rangle$ that appears in the mean momentum equation for fully developed pipe and channel flow. It represents the net fictitious force exerted by the Reynolds shear stress. This force may or may not be significant when the underlying structures are themselves varying slowly in space. In terms of the co-spectrum, the derivative is (Guala, 2006):

$\frac{\partial\left(-\overline{u \prime w^{\prime}}\right)}{\partial z}=\int_{0}^{\infty} \frac{\partial\left(-\Phi_{u w}\right)}{\partial z} d k_{x}$ 
showing that the derivative of $\Phi_{u w}$ represents the spectral contribution to the derivative of $\overline{u^{\prime} w^{\prime}}$, where the co-spectrum is the velocity tensor spectrum in which the cross-correlation is computed between the streamwise fluctuation of velocity component $(u)$ and the fluctuation of the vertical velocity component $(w)$.

Velocity components were measured using a Particle Image Velocimeter (PIV) which is a noninvasive optical measurement system, which significantly improves the spatial resolution of the measurement.

Optical methods are used throughout fluid mechanics to study fields of velocity, density, temperature, and chemical concentration (Adrian, 1986).

\section{Materials and methods}

The purpose of the experimental work is the characterization of the flow in a mobile-rough bed. Hence, the experimental tests were designed to 


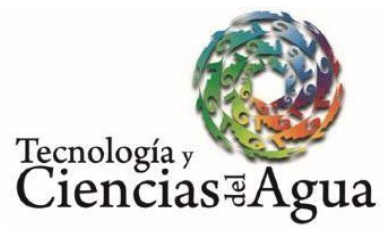

2021, Instituto Mexicano de Tecnología del Agua

Open Access bajo la licencia CC BY-NC-SA 4.0

(https://creativecommons.org/licenses/by-nc-sa/4.0/)

measure instantaneous velocities from which velocity profiles and total stress are derived. The experimental work was carried out at the Laboratory of Hydraulics and Environment of Instituto Superior Tecnico (IST) in Lisbon, Portugal, acquiring 2D velocity maps with a Particle Image Velocimetry (PIV) system. The measurements with PIV included streamwise velocity acquisitions in the vertical planes. The experimental campaign was compound by four experiments. In particular, the former is the reference test in which no sediment motion is observed, the second experiment is the one with the lowest quantity of sediment in motion, the third has medium sediment transport and the last has the highest sediment motion.

\section{Flume description}

The experiments were performed in a $0.4 \mathrm{~m}$ wide, $0.5 \mathrm{~m}$ deep, and 12.5 $\mathrm{m}$ long rectangular tilting flume. The channel has side walls made of glass, enabling flow visualization and laser measurements. During the experiments, the channel was set with different slopes and the bottom was covered with a layer of glass beads with a diameter of $5 \mathrm{~mm}$.

The flume has a recirculation circuit composed by: 
2021, Instituto Mexicano de Tecnología del Agua

Tecnología y

Ciencias $\stackrel{\Xi}{\Im}$ Aua
Open Access bajola licencia CC BY-NC-SA 4.0

(https://creativecommons.org/licenses/by-nc-sa/4.0/)

- Three storage communicating tanks of an equal capacity of $1.0 \mathrm{~m}^{3}$.

- A water recirculation PVC pipe system with 200 mm diameter.

- A centrifugal pump whose maximum discharge of $28 \mathrm{l} / \mathrm{s}$.

- A centrifugal pump with a discharge of $2.2 \mathrm{l} / \mathrm{s}$ for the recirculation of the glass beads.

As for accessories, the recirculation circuit has:

- A valve upstream of the pump.

- A valve in the compression conduit used to control the discharge.

- A $0.01 \mathrm{l} / \mathrm{min}$ precision digital electromagnetic flow meter.

At the channel inlet, there is a PVC stabilizer to reduce the fluctuation of the free surface due to the flow leaving the pressurized circuit. The recirculation pipe is fixed in the middle of the channel $1.5 \mathrm{~m}$ downstream of the main inlet; $1.0 \mathrm{~m}$ downstream of the recirculation pipe position a PVC bar was installed with a vertical small pier with $1 \mathrm{~cm}$ of diameter to reduce the influence of the secondary flow over the test section. Immediately downstream a polystyrene foil was fixed to smooth the effect of the transition from smooth to rough bed on the free surface. At the outlet, there are two orifices to discharge the flow into one of the tanks. The water is pumped in the pressurized circuit from an intermediate tank to minimize the air entrainment. The flume is equipped with a manually operated gate at the outlet. Around the test section, a 


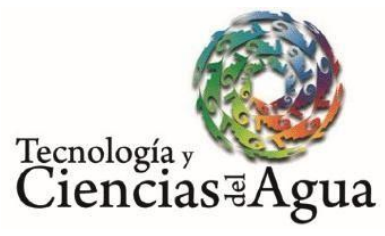

2021, Instituto Mexicano de Tecnología del Agua

Open Access bajo la licencia CC BY-NC-SA 4.0

(https://creativecommons.org/licenses/by-nc-sa/4.0/)

temporary structure was built, covered with black fabric, to avoid light penetration during the PIV measurements. The laser was mounted over a mobile carriage, equipped with a $1 \mathrm{~mm}$ precision ruler to set the desired position, able to be moved in all directions. The technique employed to measure velocities was Particle Image Velocimetry (PIV), a scheme of the PIV system considering flow direction and system reference is presented in Figure 1. It is a particle-based technique since it relies on the presence of particles following the flow. These particles are called seedings. The corresponding particles were added in the flow during the experiments in the storage tank at the outlet of the channel, to permit the mixing of the seeding with the flow during the pumping process.

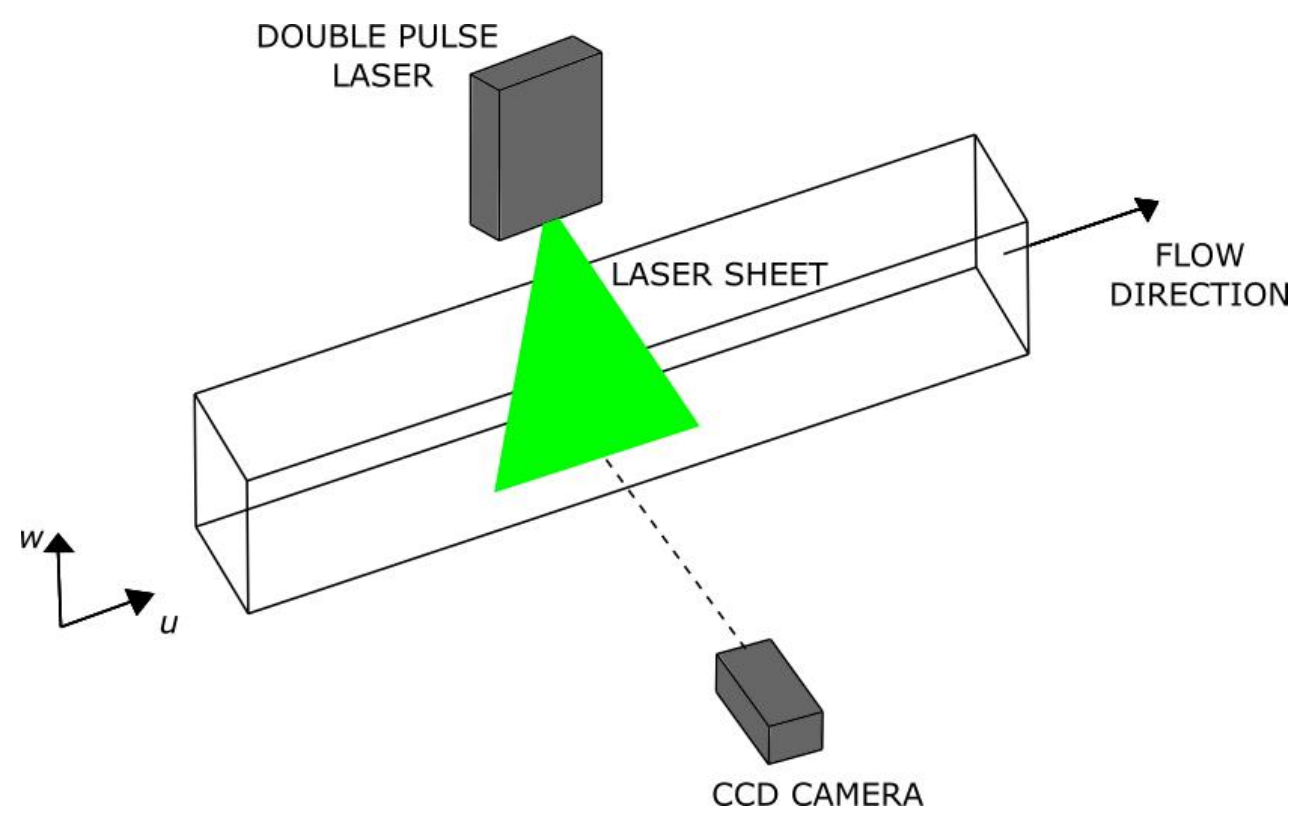

Figure 1. Scheme of the PIV system. 


\section{Instrumentation}

The 2D instantaneous velocity maps were acquired with a Particle Image Velocimetry (PIV) system. PIV is an optical technology that gives the possibility to record instantaneous velocity flow fields, by measuring the displacement of small tracer particles (also called seeding particles). From the operational point of view, PIV is a technique consisting of a laser illuminating a part of the flow and a camera recording the position of the illuminated tracer particles (Raffel, 2007).

In the tests, a classic PIV commercialized by Dantec $₫$ was used. The PIV system to measure the instantaneous velocity can be considered a non-intrusive method because it is limited to the introduction of the seeding in the flow (Raffel, 2007). In general, there is no need for part of the instrumentation in the flow region under measurement. One of the waking points of the PIV system is the large time required for the first step of raw data analysis: this process consists in converting the acquired images into instantaneous velocity fields calibrated in metric units and referenced to the channel coordinate system. 
The typical components of a PIV system are (Ferreira, 2011):

- Laser head and lens.

- Digital camera.

- Laser beam generator.

- Timing unit.

- Acquisition and control software.

The seeding particles are illuminated twice in a short period by a thin light sheet from a pulsed laser and the light scattered by the particles is captured by a digital camera in subsequent image frames. The timing unit ensures the synchronization between the light emission by the laser head and the image acquisition by the camera. The laser generator controls the power and the production of the laser light and it includes a cooling system. The system is controlled by software. The PIV system used in this experimental work was operated with a sampling rate of 15 $\mathrm{Hz}$ and its power source can generate a pulse of energy of $30 \mathrm{~mJ}$ (Reynolds, 1895).

A laser consists of the laser material (atomic or molecular gas, semiconductor or solid material), the pump source which excites the laser material, and the resonator achieved by mirror arrangement (Raffel, 2007). The laser source of the PIV system used is a double-cavity Nd:YAG laser (Neodymium-doped Yttrium Aluminium garnet), which is the most commonly used laserin modern commercial PIV systems. It is a four-level 


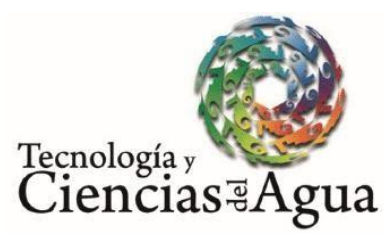

2021, Instituto Mexicano de Tecnología del Agua

Open Access bajo la licencia CC BY-NC-SA 4.0

(https://creativecommons.org/licenses/by-nc-sa/4.0/)

system that has the advantage of a relatively low laser threshold. Nd:YAG lasers are solid-state lasers (subjected to optical pumping) with high amplification and good mechanical and thermal properties. A pulsed laser is obtained by a quality switch (Q-switch) inside the cavity, operated in a software-controlled triggered mode. PIV lasers are generally associated to double oscillators, which enable the user to adjust the time gap between two illuminations of the tracer particles independently of the pulse strength.

The laser beams from each cavity are then directed to the output optics through a system of mirrors, reflectors, and shutters. At the output optics, the laser beams are passed through modular light sheet optics. The optics produce a light sheet with adjustable thickness. In this work, an 8-bit and $1600 \times 1200 p \times 2$ CCDs camera was used. CCD is an electronic sensor that can convert light into electric charge (Raffel, 2007). The sensor is only sensitive to light intensity and the flume was covered with black fabric to maximize the contrast between the illuminated particles and the black background. The camera was positioned perpendicular to the laser sheet to obtain images of the region illuminated by the laser sheet and to minimize the distortion effects. The camera and computer frequency is $15 \mathrm{~Hz}$ as the laser used.

The software used to control the data acquisition and to process the raw data was the DynamicStudio $\AA$ commercialized by Dantec $($. This software allows the user to control the acquisition mode, to set the time between pulses and the acquisition time. It also offers several control variables for data processing. The targets added into the flow have an 
important role in the quality of the data acquired with the PIV system since this technique is based on the fact that the flow tracers follow all the flow velocity fluctuation. For the present work a polymerized material, called PSP-50, was adopted. These are produced by polymerization processes and therefore have around but not exactly spherical shape. The characteristics of the seeding particle are reported in Table 1.

Table 1. Seeding particles characteristic

\begin{tabular}{|c|c|c|c|c|}
\hline $\begin{array}{c}\text { Mean particle } \\
\text { size }(\boldsymbol{\mu m})\end{array}$ & $\begin{array}{c}\text { Size } \\
\text { distribution }\end{array}$ & $\begin{array}{c}\text { Particle } \\
\text { shape }\end{array}$ & $\begin{array}{c}\text { Density } \\
\mathbf{g} / \mathbf{c m}^{\mathbf{3}}\end{array}$ & Material \\
\hline 50 & $30-70 \mu \mathrm{m}$ & $\begin{array}{c}\text { Non-spherical } \\
\text { but round }\end{array}$ & 1.03 & Polyamide 12 \\
\hline
\end{tabular}

\section{Measuring principle of a PIV system}

PIV system generates instantaneous velocity maps by measuring small displacements of seeding particles between the light pulses. The images 


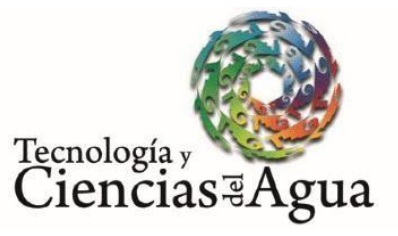

2021, Instituto Mexicano de Tecnología del Agua

Open Access bajo la licencia CC BY-NC-SA 4.0

(https://creativecommons.org/licenses/by-nc-sa/4.0/)

are divided into small areas, called interrogation areas (IA). The displacements of the illuminated (by the laser sheet) particles are obtained through the initial and final position of the particles within a given IA and for a given time between two consecutive laser pulses (Time between pulses) (Raffel, 2007). If the mean longitudinal and vertical displacements of some illuminated particles, $\Delta d x$ and $\Delta d z$, respectively, in a given interrogation area are found, the longitudinal $(u)$ and vertical $(w)$ velocities, relatively to orthogonal axes parallel to the sides, are determined by (Adrian, 1991):

$u(x, t) \approx \frac{(x+\Delta d x)-x}{\Delta t}$

$w(x, t) \approx \frac{(z+\Delta d z)-z}{\Delta t}$

where $\Delta t$ is the time between pulses, in this work, $\Delta t=850 \mu s$ to have a maximum displacement of the seeding particle equal to $20 \%$ of its diameter, between two consecutive frames; $\Delta d x$ and $\Delta d z$ are the average displacements of the particles in an IA.

The main issue in PIV data processing is to determine the most probable displacement $\Delta d x$ and $\Delta d z$ in each interrogation area with the least possible errors, to compute after the instantaneous velocity vector 


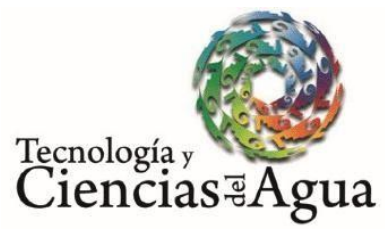

2021, Instituto Mexicano de Tecnología del Agua

Open Access bajo la licencia CC BY-NC-SA 4.0

(https://creativecommons.org/licenses/by-nc-sa/4.0/)

for each IA. Usually, the displacements are determined by crosscorrelation algorithms, that correlate the two images coming from two consecutive laser pulses $\Delta t$. There are many correlation algorithms, but the most common are those based on simple cross-correlation or adaptive correlation (Raffel, 2007).

Cross-correlation works by dividing the two compared images into a user-defined number of interrogation windows. The positions of these windows are fixed in both images. Cross-correlation is calculated only once to obtain the relative displacement between two corresponding windows. As a result, the correlated area in any two windows decreases as the displacement increases. Per contra, in adaptive correlation, the position and size of the interrogation window are continuously improved to obtain the optimal prediction (Liu \& Iskander, 2004).

In the case of adaptive correlation, as in this work, a large interrogation area is employed first and subjected to simple crosscorrelation. Then the correlation peak is used to re-center a smaller interrogation area, again subjected to correlation. This process continues while there are enough illuminated seeding particles. The first steps determine the direction of the flow, and the last step finds the correct displacements even with few illuminated particles in the interrogation area (Raffel, 2007). It is better that illuminated particles occupy an area of more than four square pixels. The values of the displacements are divided by the time between pulses to be converted into velocities. The process is repeated for all the interrogation areas in the image. The last step, called validation, is necessary to ensure good results because noisy 
interrogation areas will produce spurious velocity vectors. These vectors may be compared with their neighbors. If they fail a verisimilitude test, they are substituted, generally by the median of the surrounding eight vectors.

Raffel (2007) considers that while median filtering is frequently utilized in image processing to remove spurious vectors, it may also be applied for the efficient treatment of spurious velocity vectors. Median Test simply speaking means that all neighboring velocity vectors $U_{2 D}(n)$ are sorted linearly either with respect to the magnitude of the velocity vector, $u$, and $w$ components. The central value in this order (i.e., eight neighbors) is the median value. The velocity vector under inspection $U_{2 D}(i, j)$ is considered valid if:

$\mid U_{2 D}($ med $)-U_{2 D}(i, j) \mid<\epsilon_{\text {thresh }}$

Where $\epsilon_{\text {thresh }}$ is the threshold value for velocity vector validation.

\section{Bed description}


The bed was characterized by $3.0 \mathrm{~m}$ of the smooth bottom (PVC) downstream of the inlet, $2.5 \mathrm{~m}$ of one layer of glued spherical glass beads (5.0 $\mathrm{mm}$ diameter), after the smoothed bed, to ensure the development of a rough-wall boundary layer, a mobile reach $4.0 \mathrm{~m}$ long and $2.5 \mathrm{~cm}$ deep filled with $5.0 \mathrm{~mm}$ diameter glass beads, with density $\rho_{s}=$ $2490 \mathrm{~kg} / \mathrm{m}^{3}$, downstream of the fixed rough bed. The roughness of the bed varies in each test owing to the different conditions of solid transport.

\section{Experimental campaign and flow characteristics}

The experimental campaign consisted of four tests with different flow, slope, and solid transport characteristics. All the tests were in nonuniform flow conditions. These tests have been classified according to solid transport conditions as nil, low, medium, and high transport. Subsequently, the tests were named Test A, Test B, Test C, and Test D. Measurements were carried out using the PIV system. Each test was carried in the middle channel position. 
The characteristic parameters of the flow are reported in the following Table 2 discharge $(Q)$, slope $(S)$, wetted area $(A)$, water depth $(h)$, Reynolds number $(R e)$, Froude number $(F r)$, mean Iongitudinal velocity $(U)$. Knowing the discharge, it is possible to compute the mean flow velocity as $U=\frac{Q}{A}$, through which it is possible to compute the Reynolds number as $R e=\frac{U 4 R}{v}$, where $R$ is the hydraulic ratio and $F r=$ $U \sqrt{g h_{w}}$ the Froude number. A summary table with the parameters previously explained is reported, to have a general overview of the tests performed.

Table 2. Summary table of the performed test.

\begin{tabular}{|l|c|c|c|c|c|c|c|}
\hline Test & $\boldsymbol{Q}$ & So & $\boldsymbol{A}$ & $\boldsymbol{h}$ & $\boldsymbol{U}$ & $\boldsymbol{R e}$ & $\boldsymbol{F r}$ \\
\hline & $\mathrm{m}^{3} / \mathrm{s}$ & adim. & $\mathrm{m}^{2}$ & $\mathrm{~m}$ & $\mathrm{~m} / \mathrm{s}$ & adim. & adim. \\
\hline A & 0.015 & 0.0020 & 0.0404 & 0.0955 & 0.37 & $9.90 .10^{4}$ & 0.38 \\
\hline B & 0.016 & 0.0045 & 0.0253 & 0.0673 & 0.63 & $1.19 .10^{5}$ & 0.77 \\
\hline C & 0.016 & 0.0034 & 0.0245 & 0.0613 & 0.62 & $1.17 .10^{5}$ & 0.80 \\
\hline D & 0.0205 & 0.0040 & 0.0326 & 0.0787 & 0.63 & $1.44 .10^{5}$ & 0.71 \\
\hline
\end{tabular}




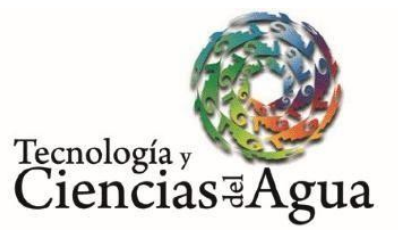

2021, Instituto Mexicano de Tecnología del Agua

Open Access bajo la licencia CC BY-NC-SA 4.0

(https://creativecommons.org/licenses/by-nc-sa/4.0/)

Test A was in nil solid transport condition. Whereas Test B, Test C, and test $D$ were in low, medium, and high solid transport conditions respectively.

\section{Preliminary raw data analysis}

The first step is the treatment of the raw PIV data. This process consists in converting the acquired images into instantaneous velocity fields calibrated in metric units. The acquisition time, according to previous works, was set equal to 5 minutes per position; 9000 images were stored in each acquisition, and they were divided in frame $A$ and frame $B$, showing the particle lightened by the laser sheet. Between frame $A$ and frame $B$, there is a time interval of $850 \mu$ s. By using the DynamicStudio $($ ) software, the instantaneous velocity vectors were extrapolated and stored in a format readable by Matlab $®$. Furthermore, in DynamicStudio $\AA$ it was adopted the adaptive correlation was to analyze the PIV signal.

This method determines the most probable displacement of the group of particles that appear in each interrogation area. 


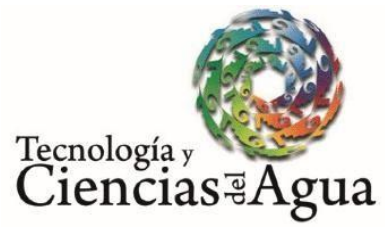

2021, Instituto Mexicano de Tecnología del Agua

Open Access bajola licencia CC BY-NC-SA 4.0

(https://creativecommons.org/licenses/by-nc-sa/4.0/)

In the adaptive correlation method, a large interrogation area is employed first and subjected to simple cross-correlation. Then the correlation peak is used to re-center a smaller interrogation area, again subjected to correlation. This process continues while there are enough illuminated seeding particles. The first steps determine the direction of the flow, and the last step finds the correct displacements even with few illuminated particles in the interrogation area. The last step, called validation, is necessary to ensure good results because noisy interrogation areas will produce spurious velocity vectors. These vectors are compared with their neighbors. If they fail a verisimilitude test, they are substituted by the median of the surrounding eight vectors.

The PIV optical technique used, calculates velocity vectors within an initial interrogation area (IA) of size $\mathrm{N}$, times the size of the final IA. It uses the intermediary results as information for the next IA of smaller size until the final IA size is reached (Dynamics, 2013). To compensate for the loss of vector field resolution during the processing, overlap of IA was fixed at $50 \%$. The number of refinements $(N)$ adopted was equal to 2. This value resulted to be a good compromise between date results and computational time. This process starts with an IA of $128 \times 128 \mathrm{p} \times 2$ to finish with an IA equal to $32 \times 32 \mathrm{p} \times 2$. In this work, the horizontal overlap was $H=50 \%$, and the vertical overlap $V=50 \%$.

Validation parameters for the adaptive correlation method are different and can also be combined to tune the processing and to remove spurious vectors. The minimum peak height ratio chosen is 1.2 . The peak validation can help to identify invalid vectors but is unable to produce an 


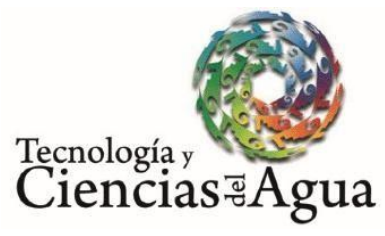

2021, Instituto Mexicano de Tecnología del Agua

Open Access bajo la licencia CC BY-NC-SA 4.0

(https://creativecommons.org/licenses/by-nc-sa/4.0/)

estimate of what the correct vector might be. Consequently, the invalidated vector will simply be substituted with zero, which can be quite far from the truth. It is strongly advised not to use peak validation alone, but always to combine it with a local neighborhood validation, which (based on neighboring vectors) is capable of making a realistic estimate of what the spurious vector should be (Dynamics, 2013).

The suggestion of the software developer was followed and was set a local neighborhood validation using a local mean. With this procedure, individual vectors are compared to the local vectors in the neighborhood vector area. If a spurious vector is detected, it is removed and replaced by a vector, which is calculated by local interpolation of the vectors present in the area. Interpolation is performed using the median methodology. But not all the vectors are related to the flow, because the frames contain parts external to the area occupied by the fluid. Hence, it is needed to mask the area that does not contain the fluid to avoid errors in the next computations. After the masking procedure, it is needed calibration of the image. The calibration process is a linear interpolation process required to compute the pixel-to-meter conversion factor to be applied to the velocity vectors previously computed with the adaptive correlation analysis. The dimension of a single square in the calibration grid is $1 \times 1 \mathrm{~cm}^{2}$. 
Tecnología y

Ciencias $\stackrel{\Xi}{\triangleleft}$ gua
2021, Instituto Mexicano de Tecnología del Agua

Open Access bajo la licencia CC BY-NC-SA 4.0

(https://creativecommons.org/licenses/by-nc-sa/4.0/)

\section{Results}

Considering the acquisition process shows in Figure 2.

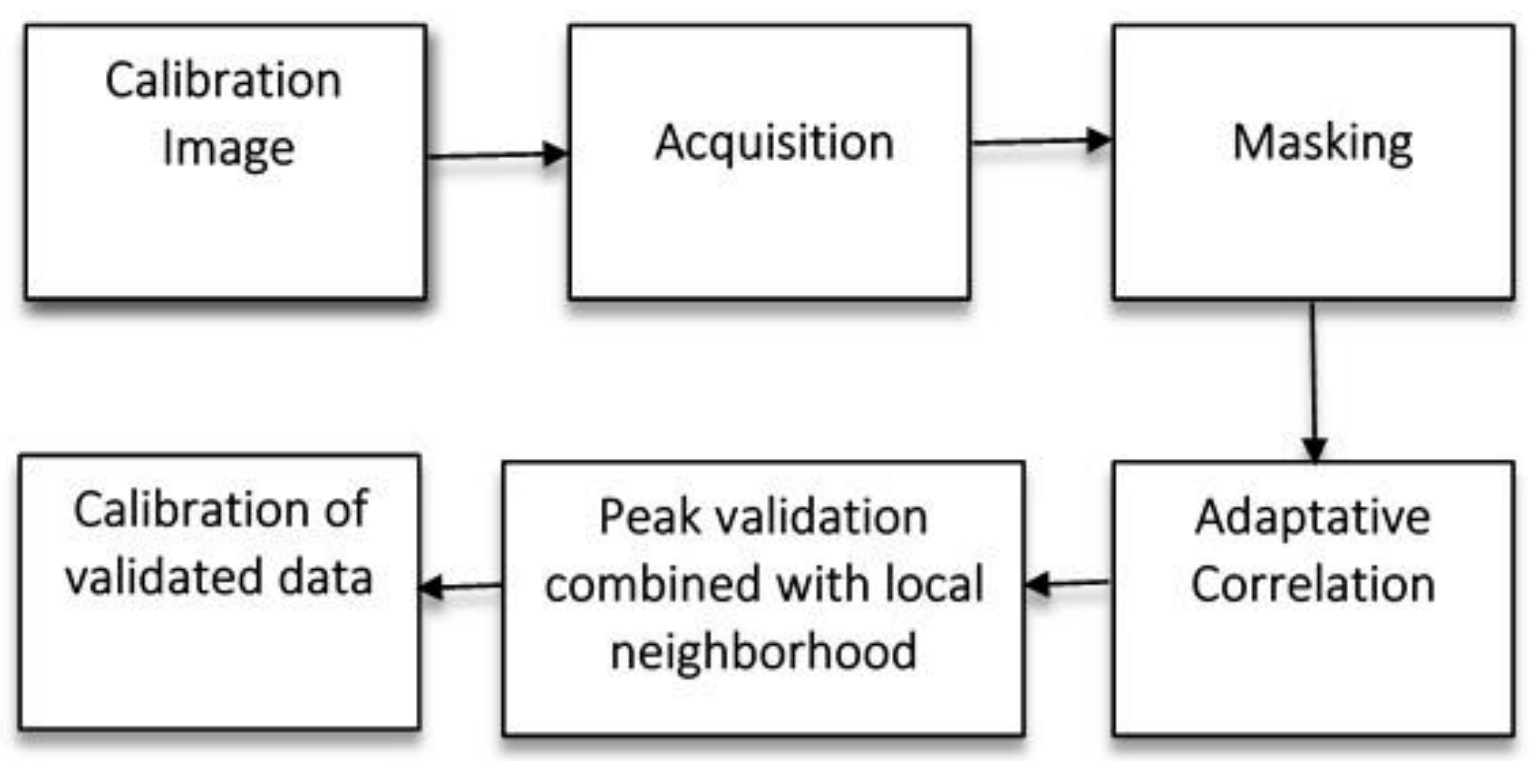

Figure 2. Data acquisition process.

Once obtained the clear data by a preliminary analysis to clean them from spurious velocity values; then, the total shearstresses are computed using two different methods and the shear stress profiles are plotted and 
compared with data from the literature. Afterward, several methods are explained to compute the velocity scale for the hydrodynamic quantities.

\section{Momentum balance analysis}

Once obtained the masked velocity maps in the correct unit, it is possible to compute the stresses related to each test. Using Equation (8) it is possible to compute the shear stresses.

$\langle\bar{\tau}\rangle=\left\langle\bar{\tau}_{f}\right\rangle+\left\langle\bar{\tau}_{x z}\right\rangle+\left\langle\bar{\tau}_{v}\right\rangle$

Preliminary tests are needed to compute the shear stress distribution using methods based on the logarithmic velocity distribution hypothesis. In the following an analysis direct to verify the existence of the log-law is carried out through a diagnostic function as reported in Stewart (2014). This function $\psi(z)$, obtained by differentiating the loglaw and rearranged in terms of $\mathrm{k}$, is rewritten as: 
Tecnología y

Ciencias $₫$ Agua
2021, Instituto Mexicano de Tecnología del Agua

Open Access bajola licencia CC BY-NC-SA 4.0

(https://creativecommons.org/licenses/by-nc-sa/4.0/)

$\psi(z)=\frac{d z}{d\langle\bar{U}\rangle} \frac{u_{*}}{z}$

A constant region of $\psi(z)$ indicates the presence of the logarithmic layer. In Figure 3 the distribution of $\psi(z)$ does not shows any constant trend in all the tests. Hence, the existence of the universal log law is not proved. The methods in the literature that compute the shear stress and then the shear velocity by using the log-law distribution will not be used in this work.

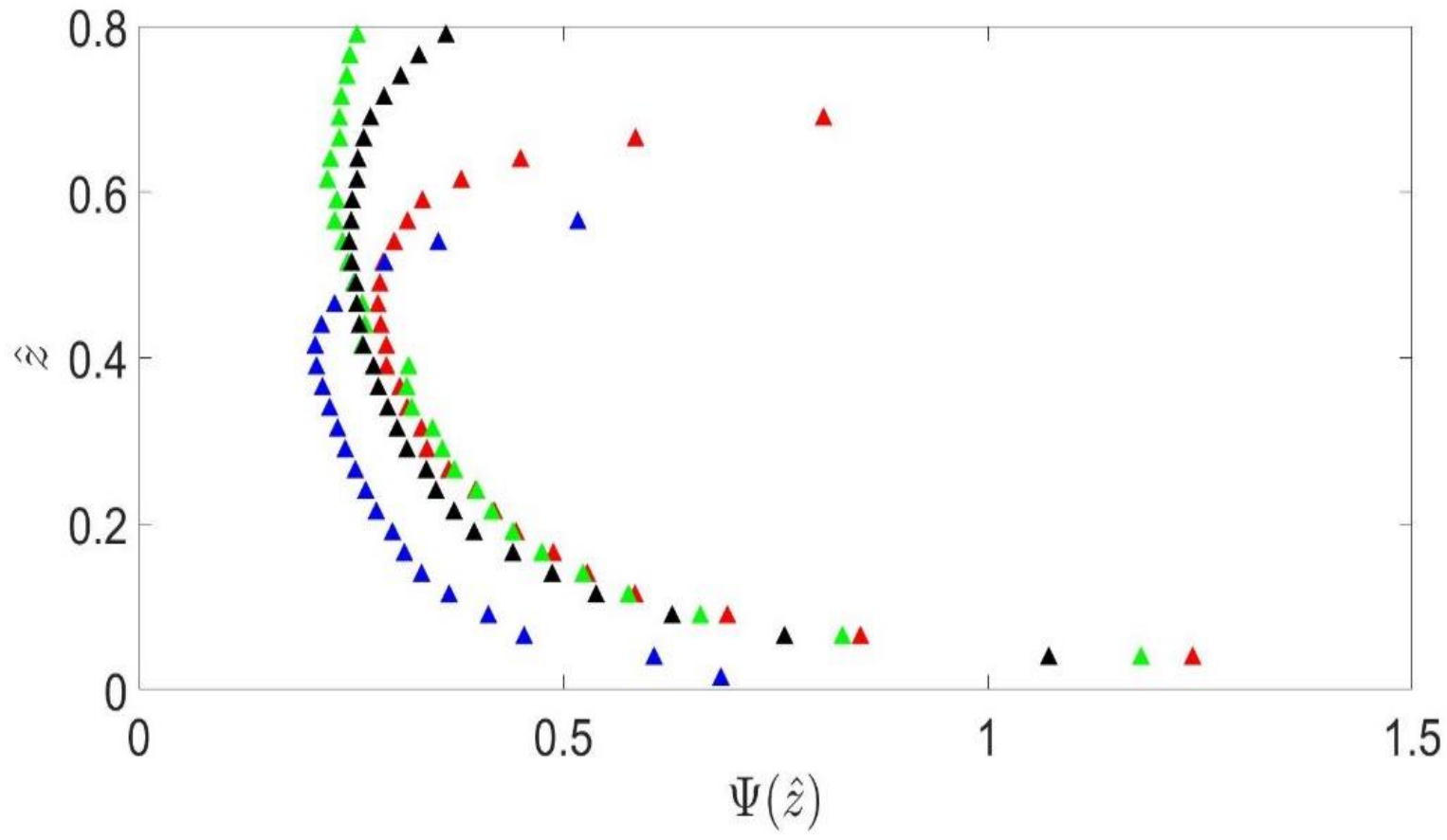


Figure 3. Behavior of the diagnostic function $\psi(z) . \triangle$ Test $A, \triangle$ Test $B$, $\Delta$ Test C and $\Delta$ Test D.

\section{Turbulent shear stress components}

Turbulent shear stress components are given by:

$\left\langle\bar{\tau}_{x z}\right\rangle=-\rho\left\langle\overline{u^{\prime} w^{\prime}}\right\rangle$

where the components $\overline{u^{\prime} w^{\prime}}$ were computed multiplying the fluctuation components and averaging the result first in time and afterward in space. The obtained DA values along the $z$-axis were multiplied by $\rho=$ $1000 \mathrm{~kg} / \mathrm{m}^{3}$ to derive the DA turbulent shear stress components.

In Figure 4 the turbulent shear stress is shown. How it is expected, with the increase of the velocity there is an increase of turbulent stress. In fact, tests $B, C$, and $D$, which are characterized by solid transport, are the ones that have the highest shear stress. The methods based on the 
Tecnología y

Ciencias $₫$ Agua
2021, Instituto Mexicano de Tecnología del Agua

Open Access bajo la licencia CC BY-NC-SA 4.0

(https://creativecommons.org/licenses/by-nc-sa/4.0/)

uniform flow condition are not considered in this work, owing to the lack of linearity of the stresses.

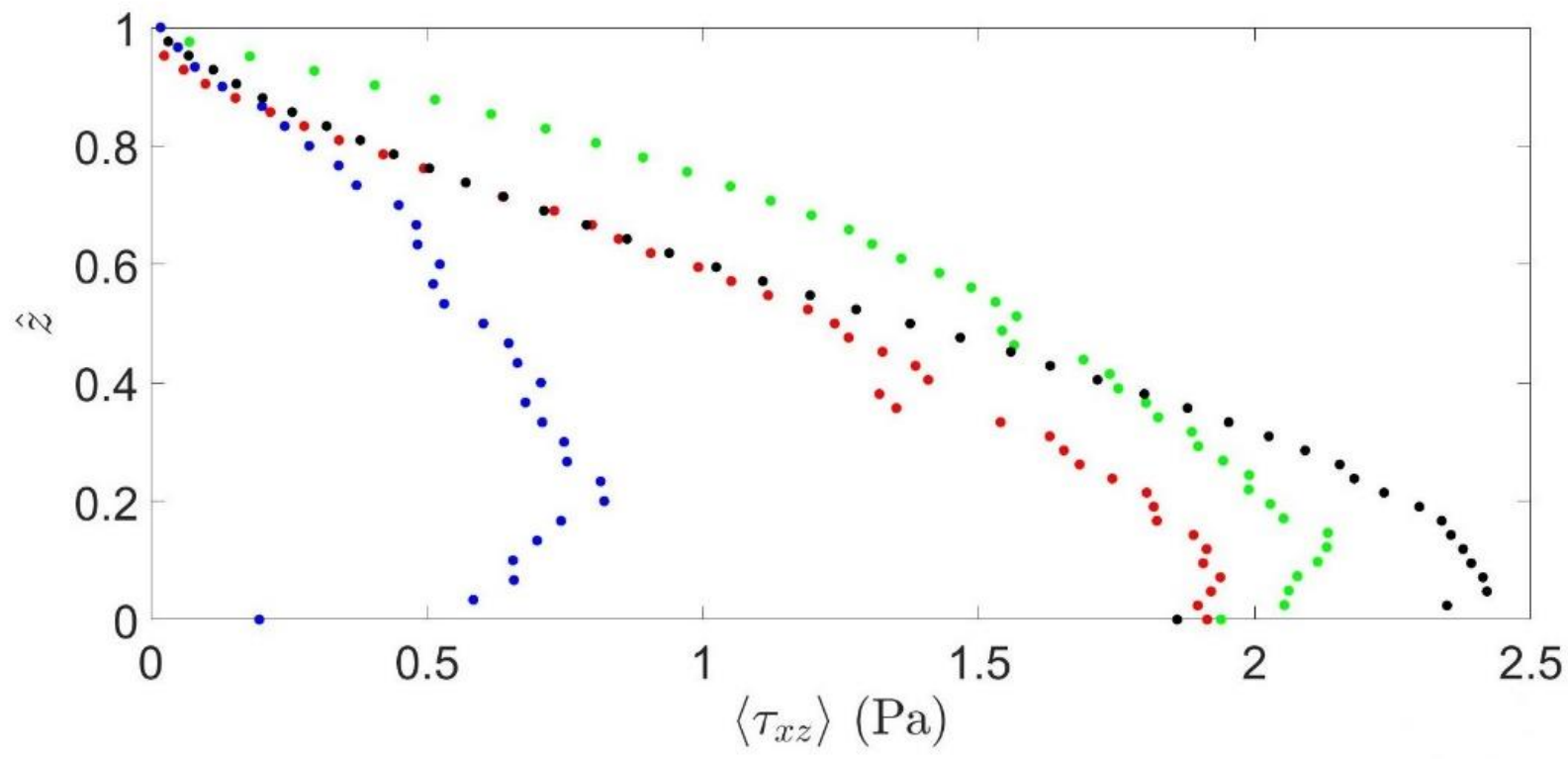

Figure 4. Turbulent shear stress components referred to: 0 Test $A, O$ Test $\mathrm{B}, \bullet$ Test $\mathrm{C}$ and $\bullet$ Test $\mathrm{D}$.

Form induced shear stress components 
Form induced shear stress components are equal to:

$\left\langle\bar{\tau}_{f}\right\rangle=-\rho\langle\tilde{u} \widetilde{w}\rangle$

Performing the product between $\tilde{u}$ and $\widetilde{w}$ and computing its spatial average, we obtain the value $\left\langle\widetilde{u_{\imath}} \tilde{u}_{J}\right\rangle$, which, multiplied by the water density $\rho=1000 \mathrm{~kg} / \mathrm{m}^{3}$, returns the stress value induced by the roughness along with the measured profile (z-direction). Figure 5 shows the time-averaged turbulent shear stress $\left\langle\bar{\tau}_{x z}\right\rangle$, the DA form-induced shear stress $\left\langle\bar{\tau}_{f}\right\rangle$ and the DA total shear stress $\langle\tau\rangle$. 

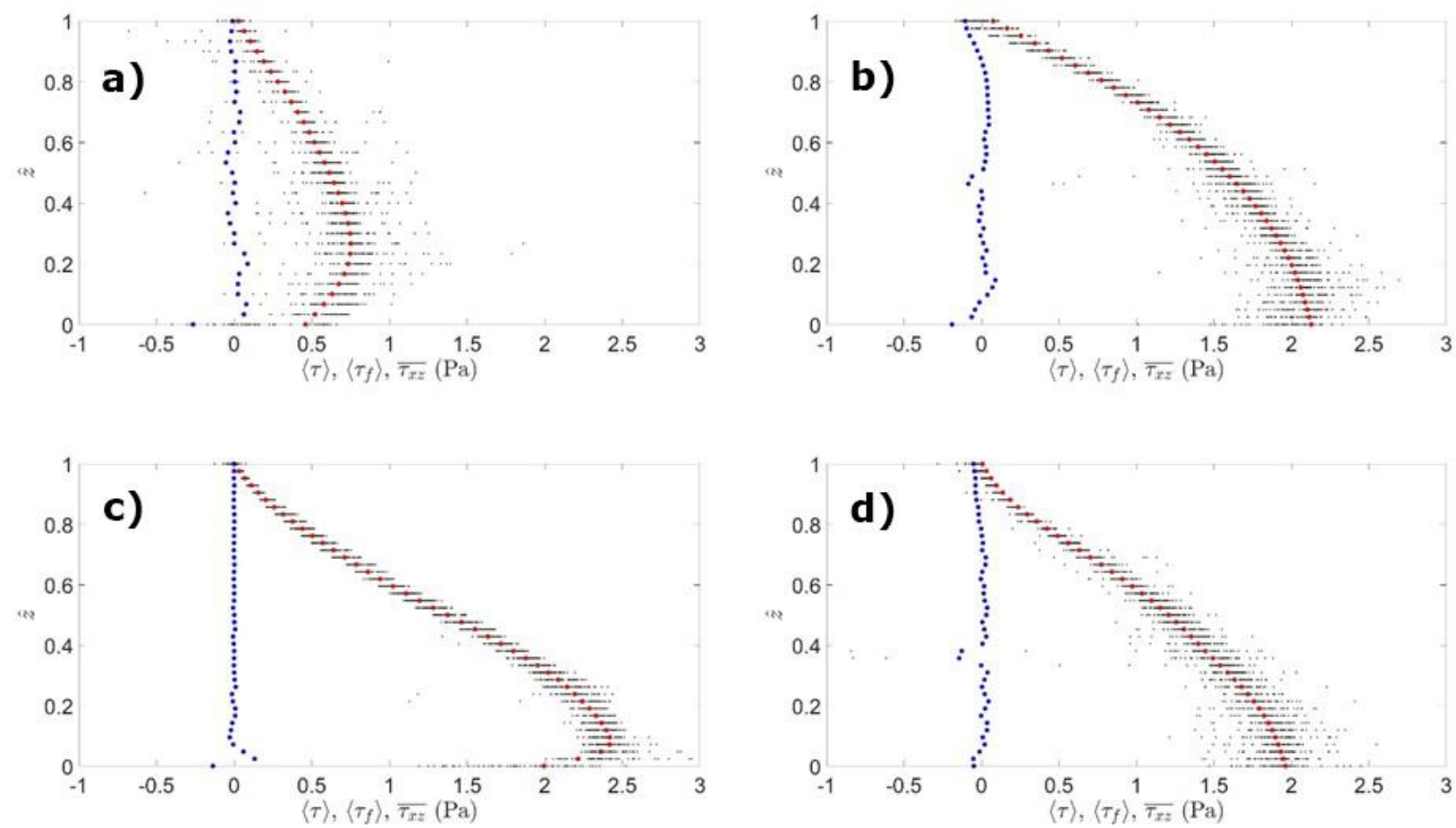

Figure 5. Time-averaged turbulent shear stress $\overline{\tau_{X Z}}, \circ$ DA form-induced shear stress $\left\langle\tau_{f}\right\rangle$, $\bullet$ DA total shear stress referred to a) Test A; b) Test $B$; c) Test C, and d) Test D.

For each test, form-induced stress profiles were computed. Figure 6 shows the form-induced $\left\langle\bar{\tau}_{f}\right\rangle$ shear stress profiles for the experiments performed. 


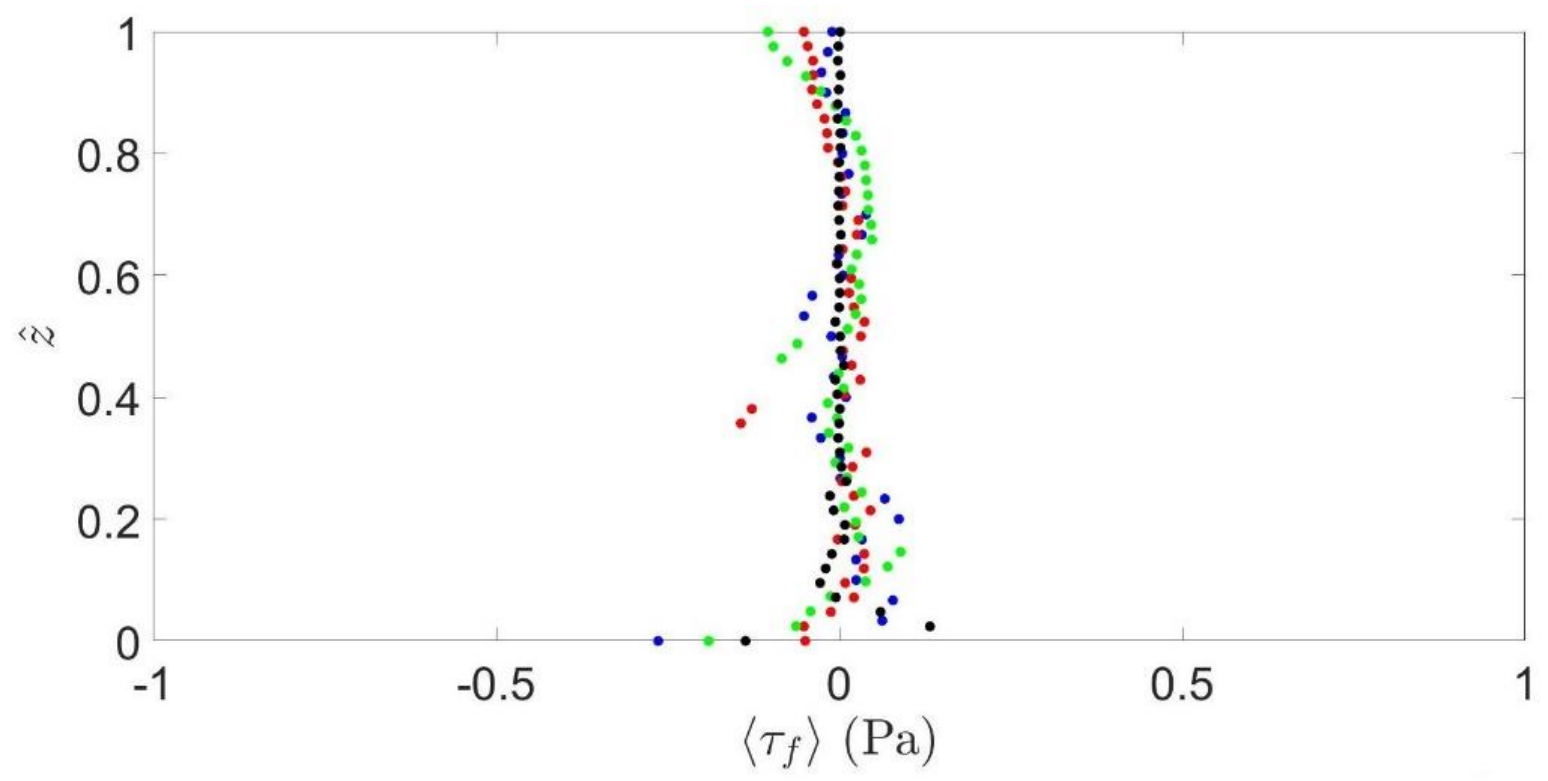

Figure 6. Form induced shear stress components referred to: $\odot$ Test $A$, - Test $\mathrm{B}, \bullet$ Test $\mathrm{C}$ and $\bullet$ Test $\mathrm{D}$.

The form-induced stresses $\left\langle\bar{\tau}_{f}\right\rangle$ can be approximated to zero for most the part of the water depth. There are some differences near the bed, congruently with the roughness, as expected; in the upper part, the differences are due to the non-uniform condition of the tests.

\section{Viscous shear stress components}


Viscous shear stress components are given by:

$$
\left\langle\bar{\tau}_{v}\right\rangle=\rho v \frac{d u}{d x}
$$

According to the Reynolds numbers of this work, the viscous sublayer, in which the $\left\langle\bar{\tau}_{v}\right\rangle$ is not negligible, is smaller than the IA. Hence, it cannot be computed.

\section{Total shear stress}

Summing up the form induced and turbulent shear stresses, the total shear stress is obtained for each experiment. The $\langle\bar{\tau}\rangle$ distribution along the water depth is shown in Figure 7. 


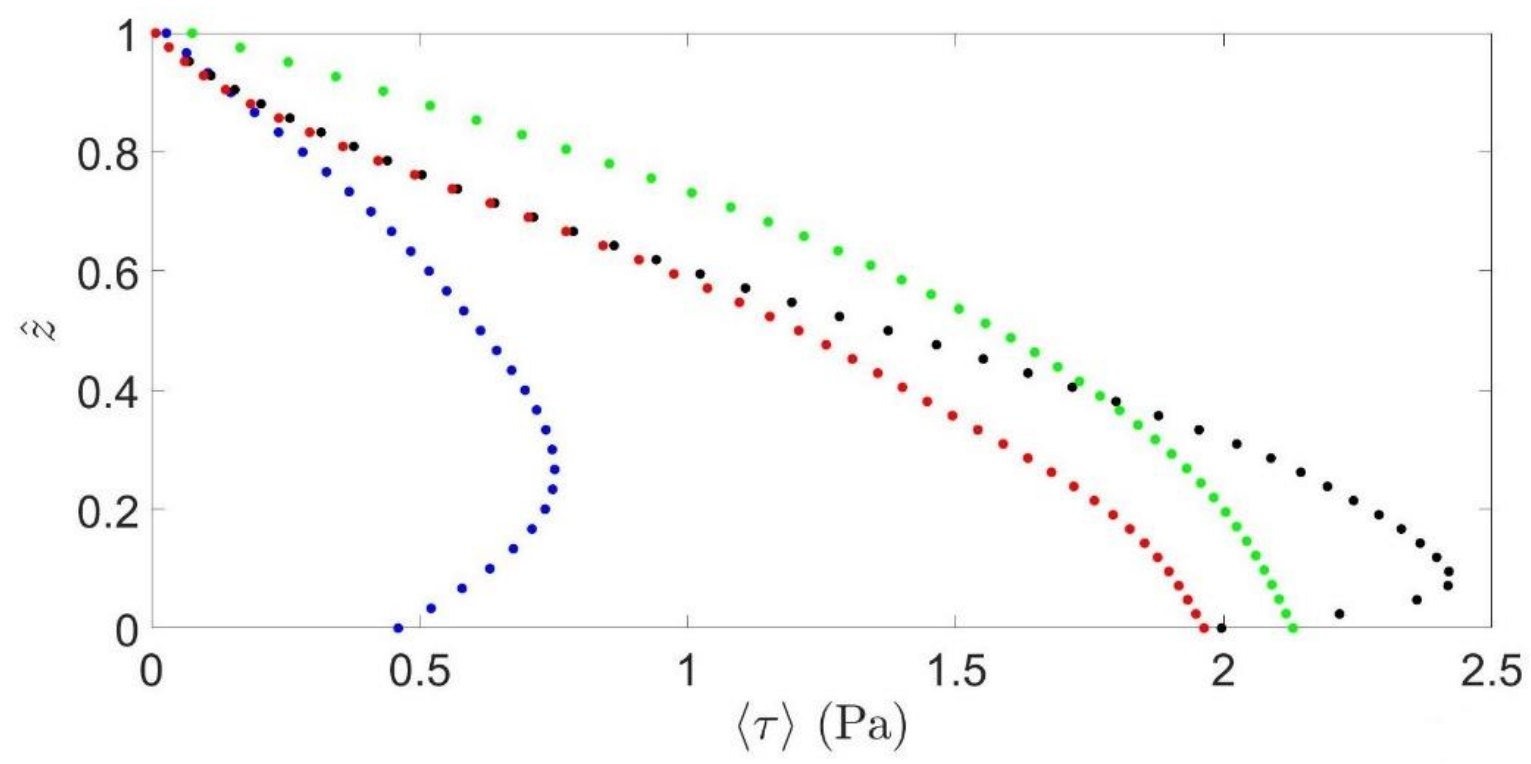

Figure 7. Total shear stress component referred to: $\odot$ Test $A$, $\odot$ Test $B$, - Test $\mathrm{C}$ and $\bullet$ Test D.

As expected, the values of $\langle\bar{\tau}\rangle$ are higher for tests $B, C$, and $D$, in which solid transport is present than for test $A$.

\section{Large scale shear stress from co-spectra integral.}


Teçnología y

Ciencias $\stackrel{\Xi}{\Im}$ Aua
2021, Instituto Mexicano de Tecnología del Agua

Open Access bajo la licencia CC BY-NC-SA 4.0

(https://creativecommons.org/licenses/by-nc-sa/4.0/)

An alternative method to compute the shear stress is based on the computation of the two-point spatial correlation relative to the velocity fluctuations $u^{\prime}$ and $w^{\prime}$ and subsequent determination of the co-spectra $\left(\Phi_{u w}\right)$ of the fluctuations. Cross spectral analysis allows determining the relationship between two time/space series as a function of frequency. The spatial velocity fluctuation has been used to compute the correlation function (two-point-spatial correlation) and then the co-spectra (Figure 8). As expected, the energy is highest near the bed and lowest near the surface.

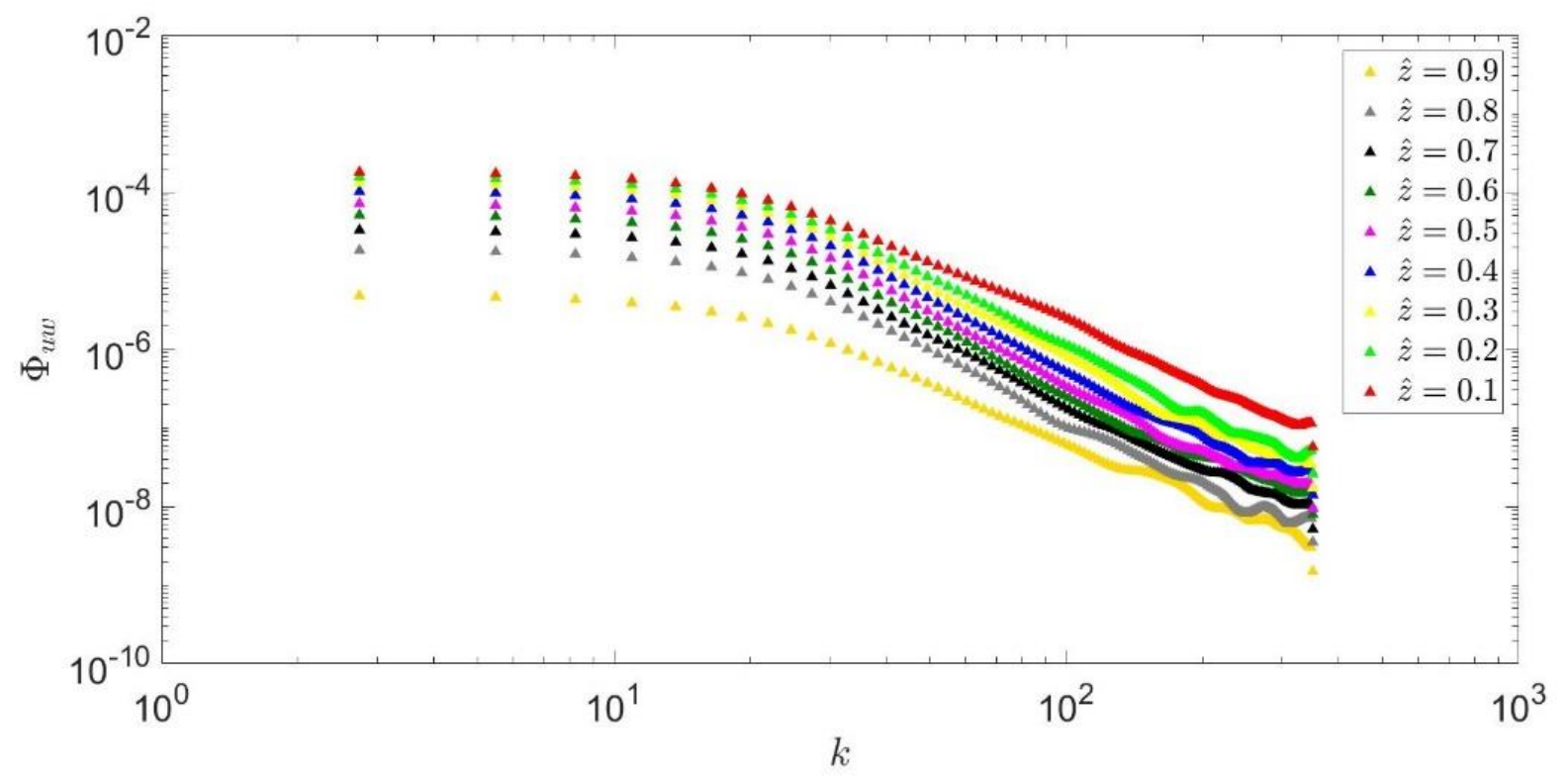

Figure 8. Co-spectra at different $\hat{z}$. 
Tecnología y

Ciencias $₫$ Agua
2021, Instituto Mexicano de Tecnología del Agua

Open Access bajo la licencia CC BY-NC-SA 4.0

(https://creativecommons.org/licenses/by-nc-sa/4.0/)

Finally, the shear stress was calculated through the integral of the co-spectra at each $z$ (see the equation below):

$\frac{\partial\left(-\overline{u^{\prime} w^{\prime}}\right)}{\partial z}=\int_{0}^{\infty} \frac{\partial\left(-\Phi_{u w}\right)}{\partial z} d k_{x}$

Figure 9 shows the shear stress profile related to each test computed with the procedure shown in Guala (2006).

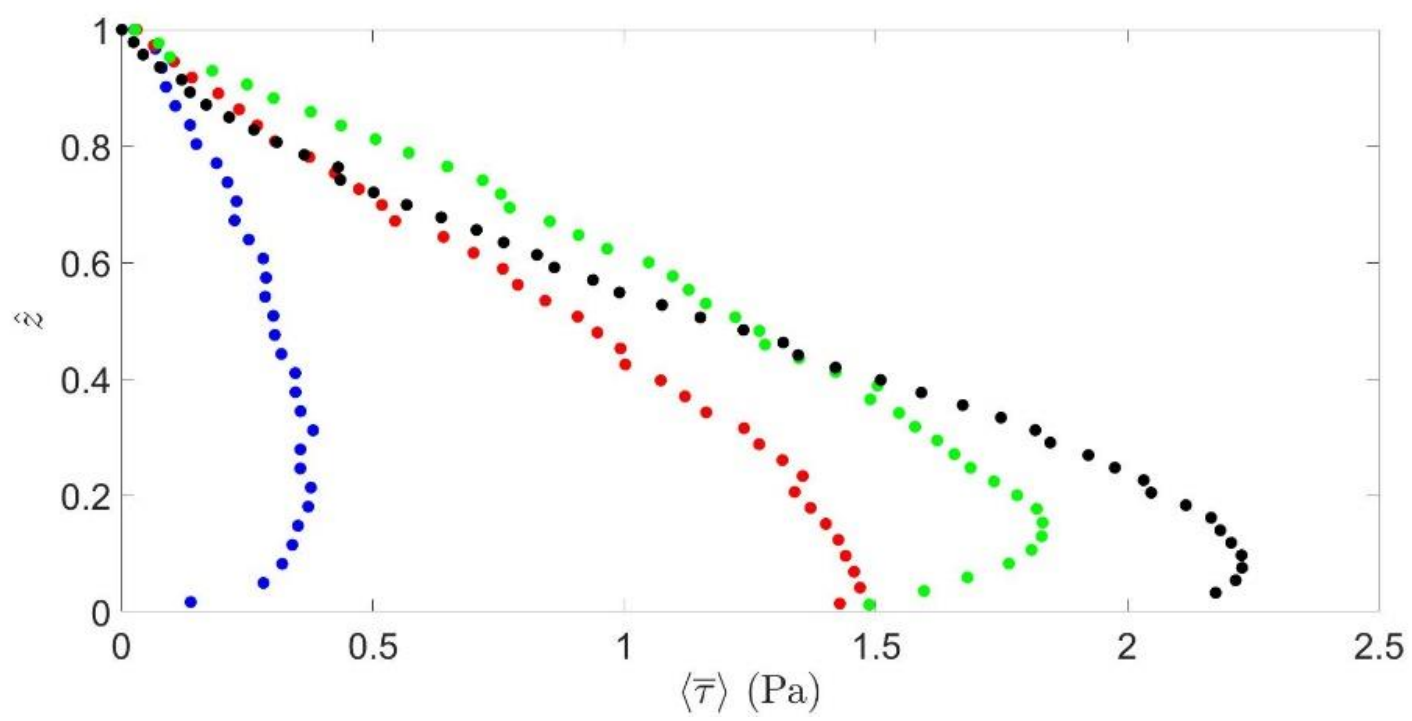

Figure 9. Large scale shear stress $\left(\langle\bar{\tau}\rangle_{(\text {(quw) }}\right)$ referred to: $\odot$ Test $A$. Test $\mathrm{B}, \bullet$ Test $\mathrm{C}$ and $\bullet$ Test $\mathrm{D}$. 
Tecnología y

Ciencias $₫$ Agua
2021, Instituto Mexicano de Tecnología del Agua

Open Access bajo la licencia CC BY-NC-SA 4.0

(https://creativecommons.org/licenses/by-nc-sa/4.0/)

Whit respect to the shear stress previously computes, the behavior seems to be similar, maintaining the same magnitude. There are smaller values of shear stress for the test without solid transport and higher values for the test with solid transport. It should be emphasized that this method returns the shear stress related to the integration range of the spatial increments of the PIV grid.

\section{Turbulent shear stress analysis}

Several procedures, found in the technical literature will be analyzed, to compute the shear stress. Furthermore, a target shear stress will be proposed to be a shear stress scale.

\section{Procedure 1}


Tecnología y

Ciencias $₫$ Agua
2021, Instituto Mexicano de Tecnología del Agua

Open Access bajo la licencia CC BY-NC-SA 4.0

(https://creativecommons.org/licenses/by-nc-sa/4.0/)

The first procedure computes the shear stress as $\left\langle\overline{u^{\prime} w^{\prime}}\right\rangle$ and sets the target shear stress as the maximum value (Figure 10). The values of $\tau_{0}$ computed according to procedure 1 are reported in Table 3.

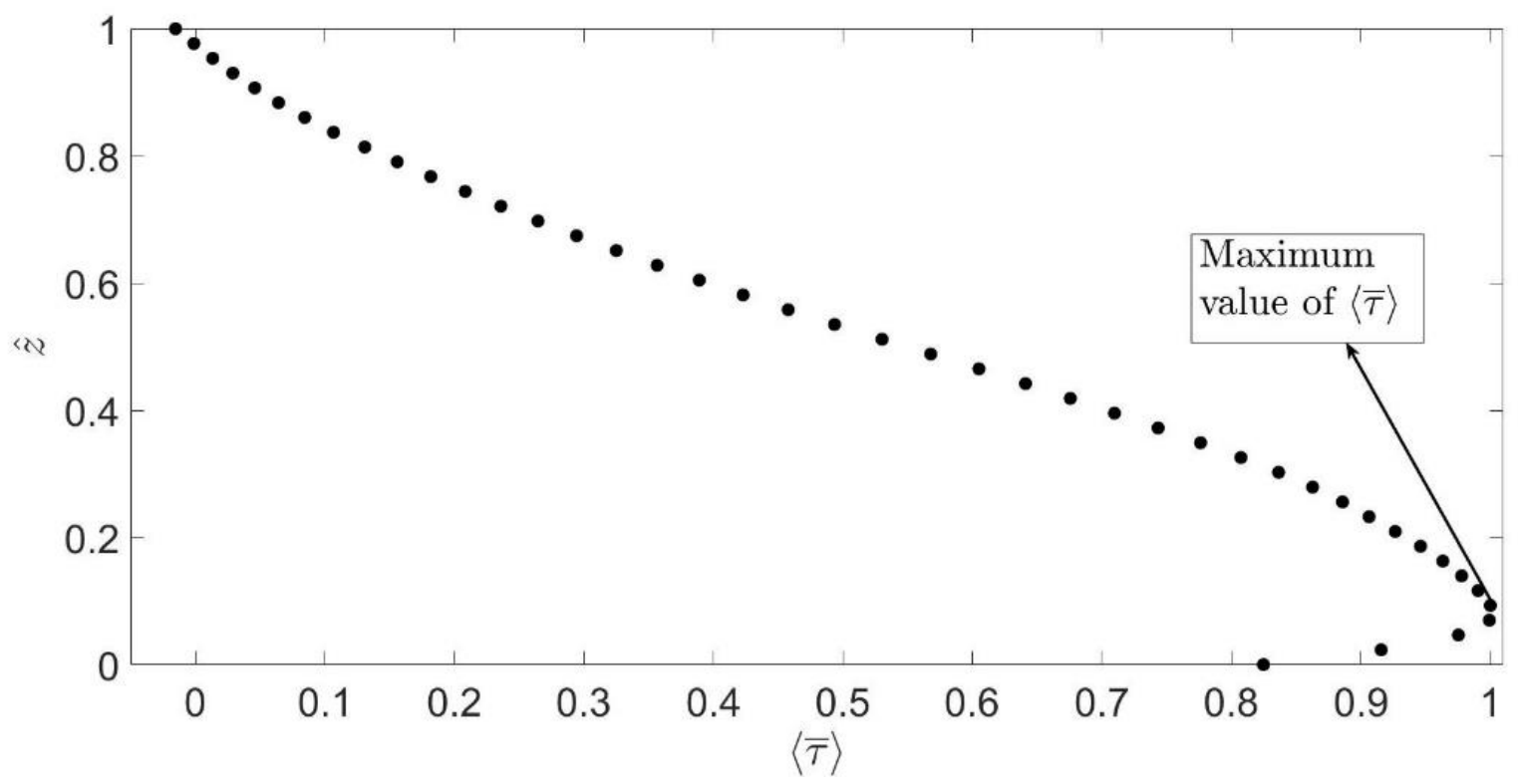

Figure 10. A scheme that shows the criteria to select $\tau_{0}$ for procedure 1.

Table 3. Values of $\tau_{01}$ obtained with procedure 1 .

\begin{tabular}{|l|l|l|l|l|}
\hline & Test A & Test B & Test C & Test D \\
\hline
\end{tabular}




\begin{tabular}{|c|c|c|c|c|}
\hline & $(\mathrm{Pa})$ & $(\mathrm{Pa})$ & $(\mathrm{Pa})$ & $(\mathrm{Pa})$ \\
\hline$\tau_{01}$ & 0.75 & 2.13 & 2.42 & 1.96 \\
\hline
\end{tabular}

Figure 11 report the non-dimensional shearstress profiles using the value of $\tau_{01}$ set with procedure 1 . Test $A$ has its maximum value at $\hat{z}=$ 0.25 , Test $C$ at $\hat{z}=0.10$, while Test $B$ and $D$ reach the maximum value at the crest level.

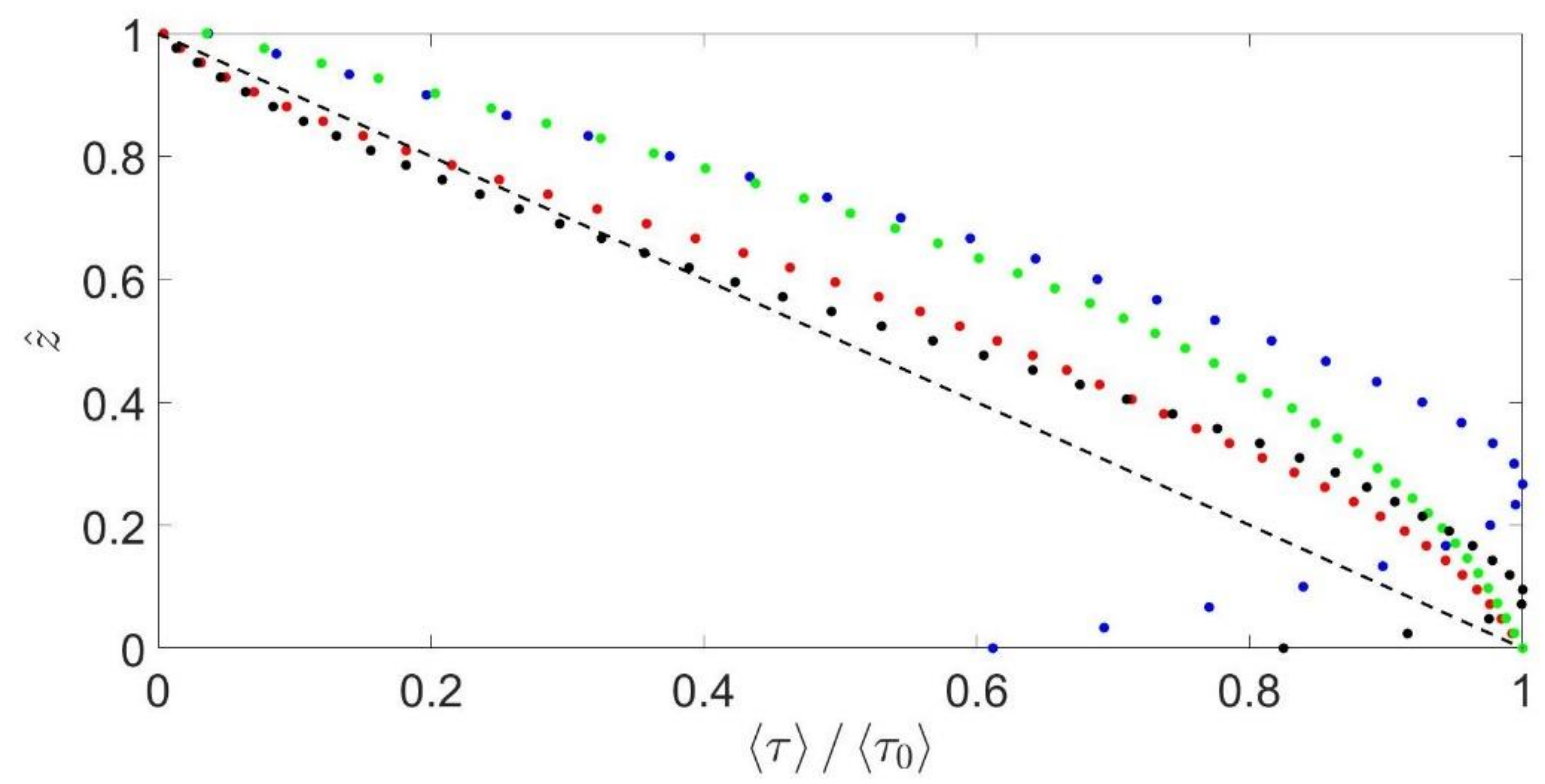

Figure 11. Non-dimensional shear stress profiles using $\tau_{01}$ computed from procedure 1 ( $\odot$ Test $A$, $\odot$ Test $B, \bullet$ Test $C$ and $\bullet$ Test $D$, and --gravity line). 
Tecnología y

Ciencias $\approx$ Agua
2021, Instituto Mexicano de Tecnología del Agua

Open Access bajo la licencia CC BY-NC-SA 4.0

(https://creativecommons.org/licenses/by-nc-sa/4.0/)

\section{Procedure 2}

The second procedure used to compute the shear stress sets the target shear stress as the value at the crest level (Figure 12). The values of $\tau_{02}$ computed according to procedure 2 are reported in Table 4.

Table 4. Values of $\tau_{02}$ obtained with procedure 2 .

\begin{tabular}{|c|c|c|c|c|}
\hline & Test A & Test B & Test C & Test D \\
\hline & $(\mathrm{Pa})$ & $(\mathrm{Pa})$ & $(\mathrm{Pa})$ & $(\mathrm{Pa})$ \\
\hline$\tau_{02}$ & 0.45 & 2.12 & 1.99 & 1.96 \\
\hline
\end{tabular}




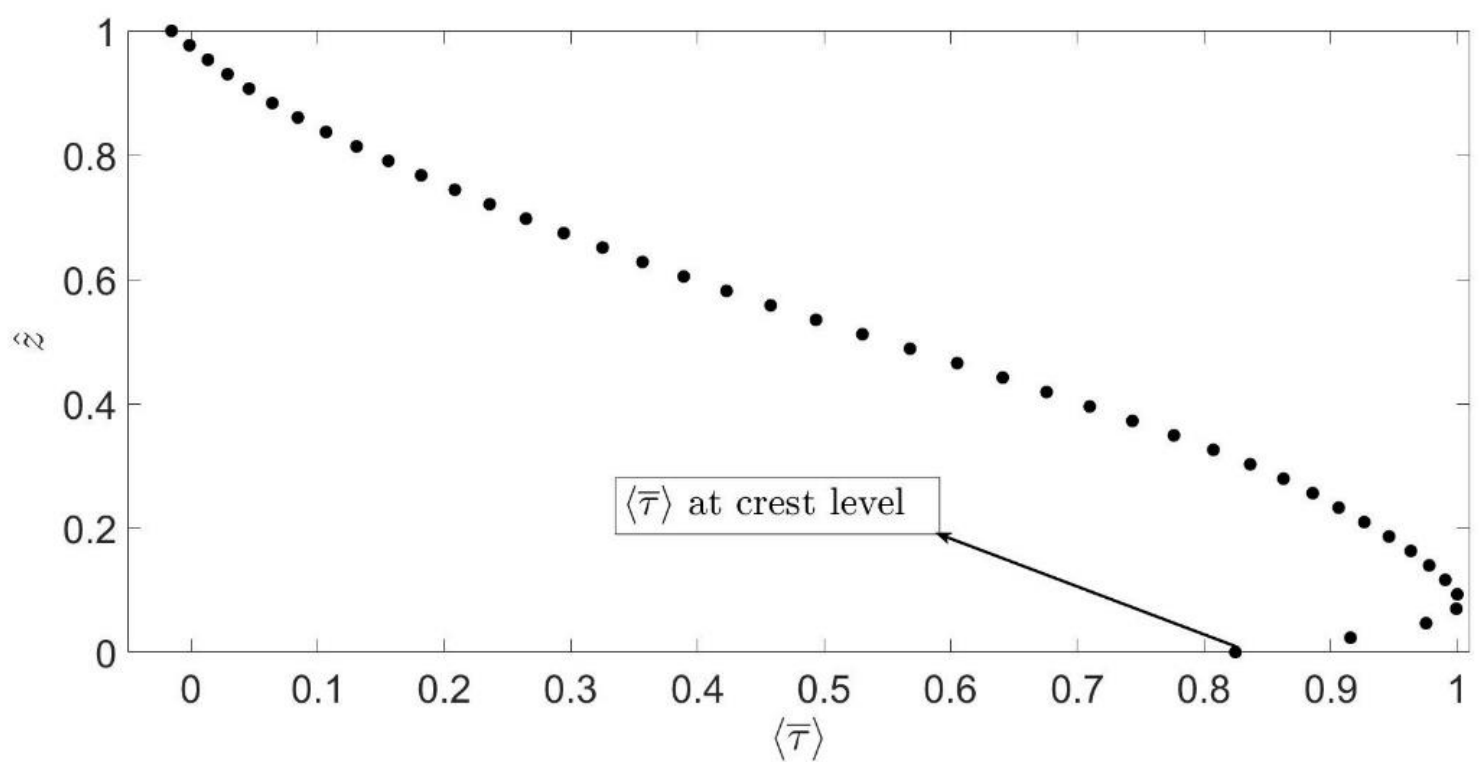

Figure 12. A scheme that shows the criteria to select $\tau$ for procedure 2 .

Figure 13 shows a high deviation of the non-dimensional profiles, scaled using the value of $\tau_{02}$ set by procedure 2 , concerning the first procedure used, and allow understanding that the values of the shear stress profile at the bed level seem to not be a good choice for this work. 


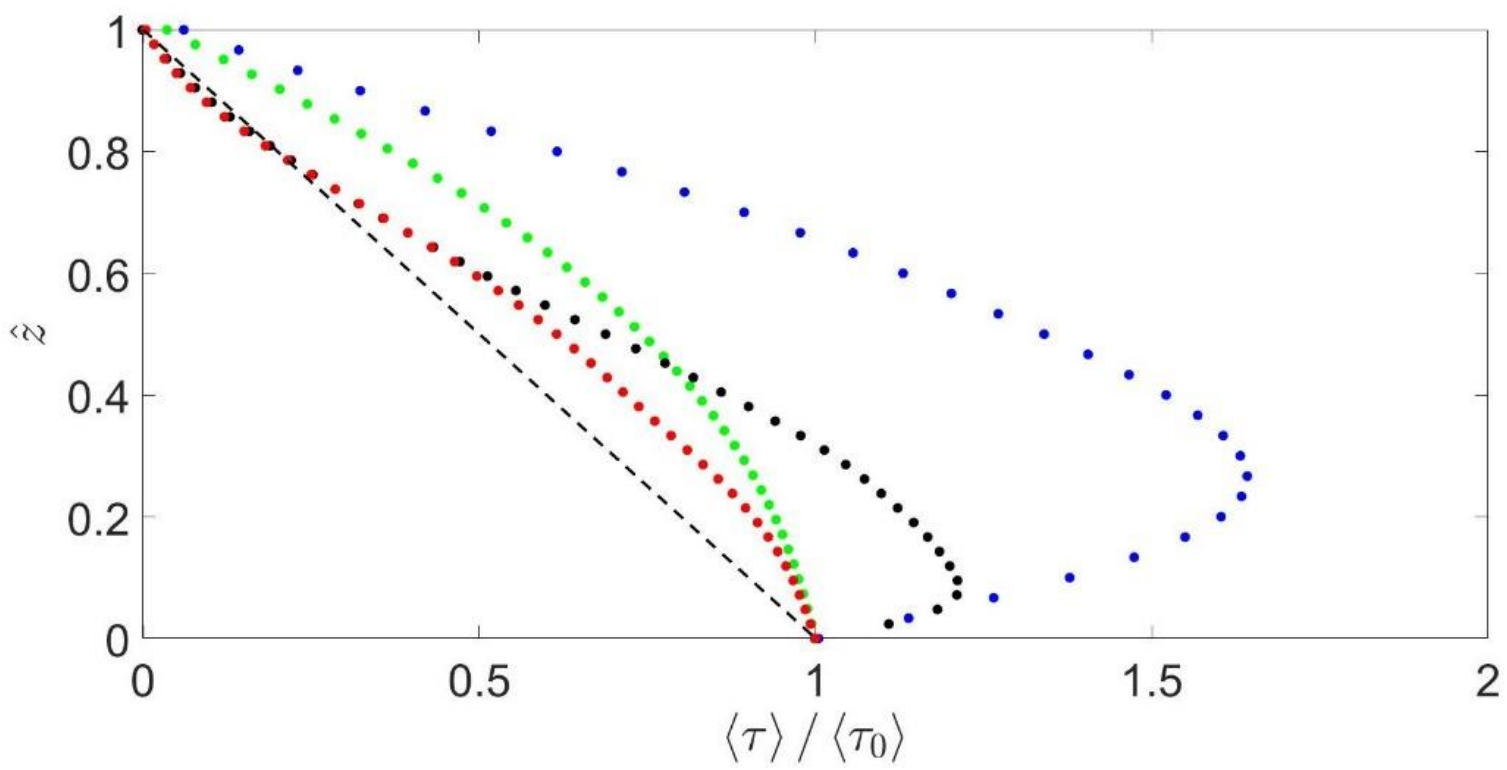

Figure 13. Non-dimensional shear stress profiles using $\tau_{02}$ computed from procedure 2 ( $\odot$ Test $A$, $\odot$ Test $B, \bullet$ Test $C$ and $\bullet$ Test $D$ and --gravity line).

\section{Procedure 3}

The third procedure used to compute the shear stress sets the target shear stress as the value at the crest level from a linear regression of the shear stress profile (Figure 14). 
Tecnología y

Ciencias $₫$ Agua
2021, Instituto Mexicano de Tecnología del Agua

Open Access bajo la licencia CC BY-NC-SA 4.0

(https://creativecommons.org/licenses/by-nc-sa/4.0/)

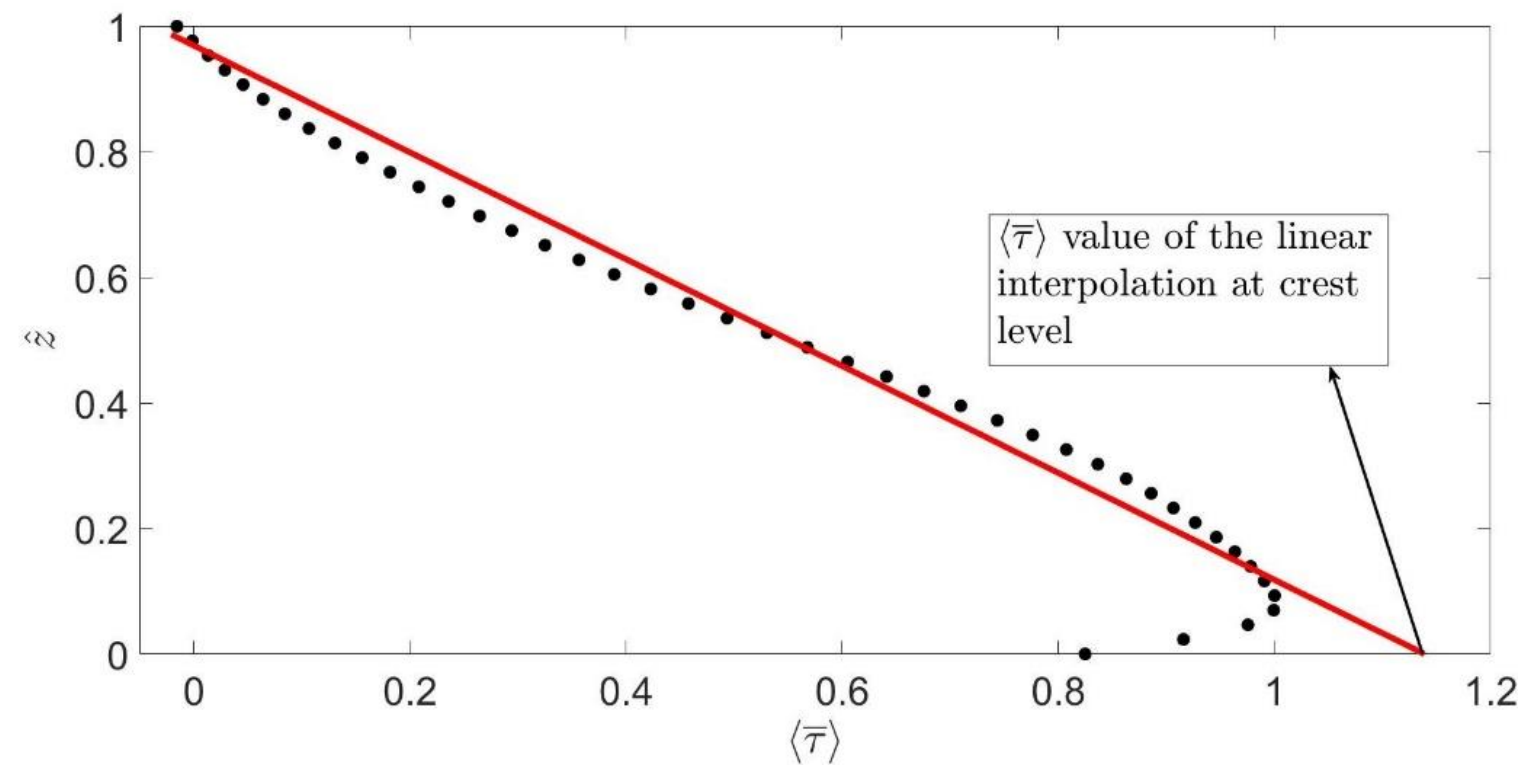

Figure 14. A scheme that shows the criteria to select $\tau$ for procedure 3 .

The values of $\tau_{03}$ computed according to procedure 3 are reported in Table 5.

Table 5. Values of $\tau_{03}$ obtained with procedure 3 .

\begin{tabular}{|c|c|c|c|c|}
\hline & Test A & Test B & Test C & Test D \\
\hline & $(\mathrm{Pa})$ & $(\mathrm{Pa})$ & $(\mathrm{Pa})$ & $(\mathrm{Pa})$ \\
\hline
\end{tabular}




\begin{tabular}{|l|l|l|l|l|}
\hline$\tau_{03}$ & 0.89 & 2.65 & 2.72 & 2.08 \\
\hline
\end{tabular}

Figure 15 shows a low deviation of the scaled shear stress profile computed using the value of $\tau_{03}$, concerning the previous methods. The shear stress derived using procedure 3 shows a proper nondimensionalization compared to the previous procedures. In fact, above $\hat{z}=0.2$ the scaled shear stresses are contained in a fairly narrow band.

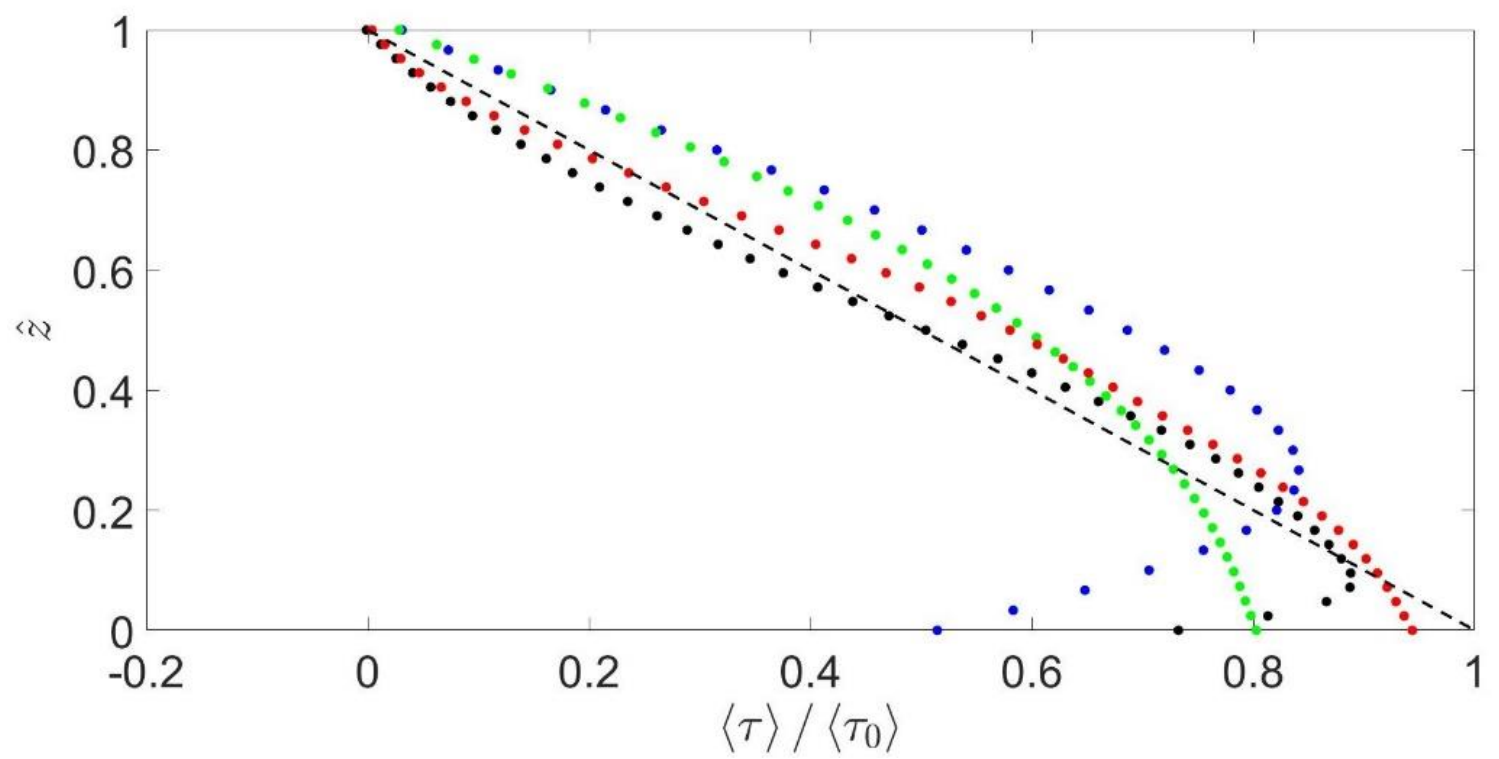

Figure 15. Non-dimensional shear stress profiles using т03 computed from procedure 3 ( $\bullet$ Test $A$, $\odot$ Test $B, \bullet$ Test $C$ and $\bullet$ Test $D$ and --gravity line). 
Tecnología y

Ciencias $₫$ Agua
2021, Instituto Mexicano de Tecnología del Agua

Open Access bajo la licencia CC BY-NC-SA 4.0

(https://creativecommons.org/licenses/by-nc-sa/4.0/)

Procedure 4

The fourth procedure used to compute the shear stress sets the target shear stress as the value at the negligible form-induced stress level extrapolated from a linear fit of the shear stress profiles (Figure 16).

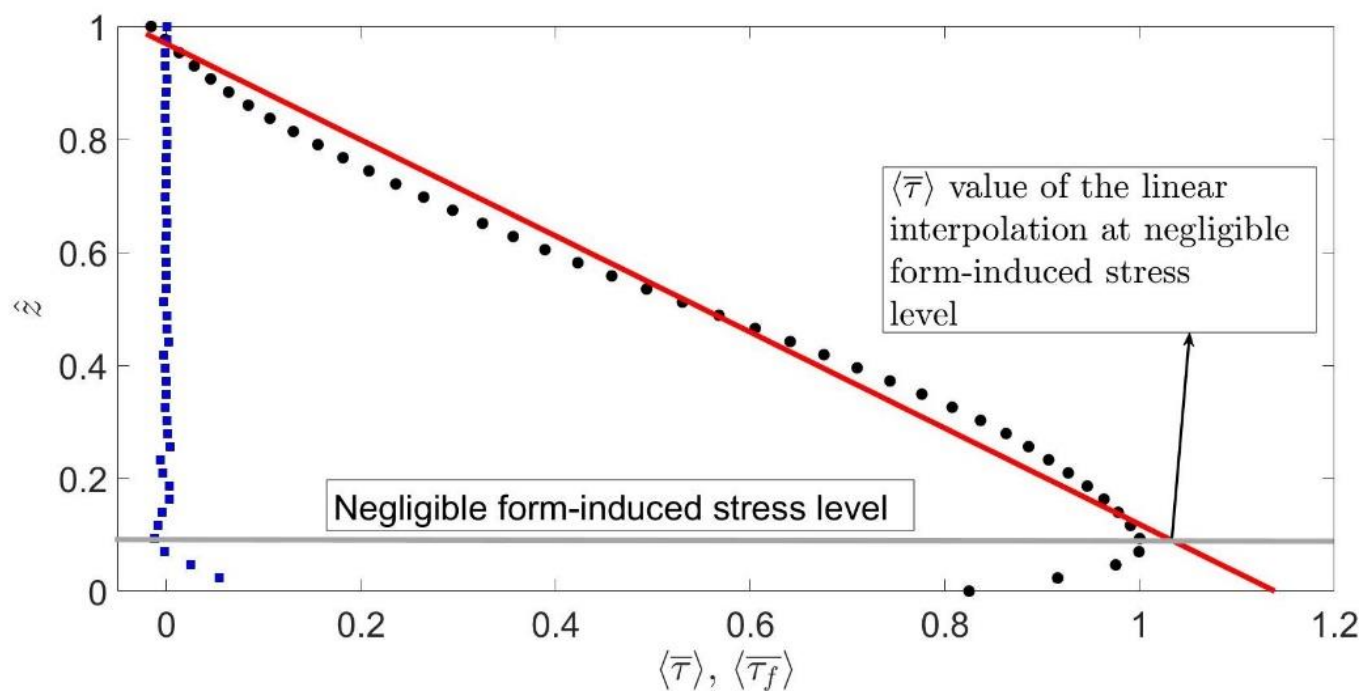

Figure 16. A scheme that shows the criteria to select $\tau$ for procedure 4 . 
Tecnología y

Ciencias $\approx$ Agua
2021, Instituto Mexicano de Tecnología del Agua

Open Access bajo la licencia CC BY-NC-SA 4.0

(https://creativecommons.org/licenses/by-nc-sa/4.0/)

The values of $\tau_{04}$ computed according to procedure 4 are reported in Table 6.

Table 6. Values of $\tau_{04}$ obtained with procedure 4.

\begin{tabular}{|c|c|c|c|c|}
\hline & Test A & Test B & Test C & Test D \\
\hline & $(\mathrm{Pa})$ & $(\mathrm{Pa})$ & $(\mathrm{Pa})$ & $(\mathrm{Pa})$ \\
\hline$\tau_{04}$ & 0.69 & 2.62 & 2.53 & 1.99 \\
\hline
\end{tabular}

Figure 17 shows a high deviation of the non-dimensional shear stress, computed using the value of $\tau_{04}$, for Procedures 1 and 3 , whereas for procedure 2 the deviation is comparable, according to the nondimensional shear stress profile previously computed. 


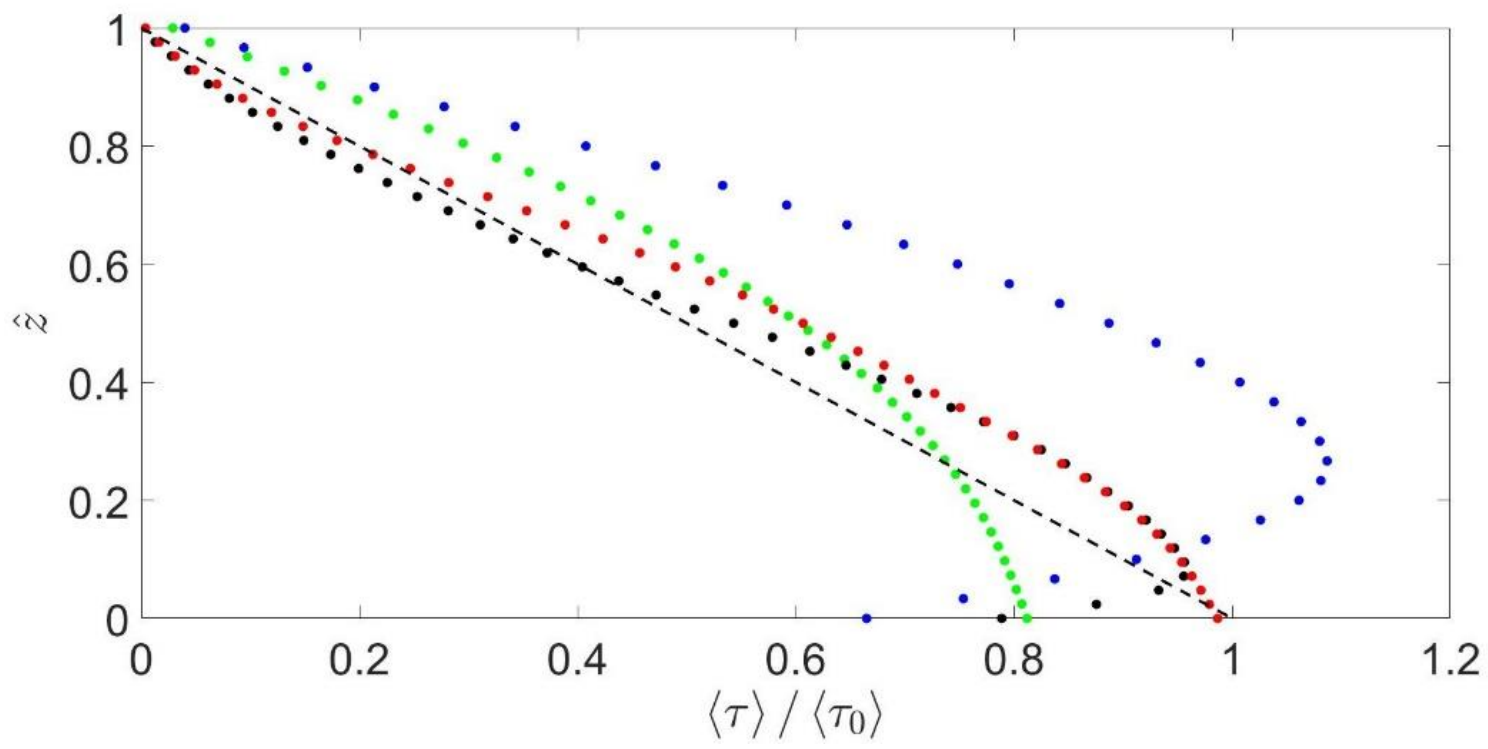

Figure 17. Non-dimensional shear stress profiles using $\tau_{04}$ computed from procedure 4 ( $\odot$ Test $A$, $\odot$ Test $B, \bullet$ Test $C$ and $\bullet$ Test $D$ and --gravity line).

\section{Procedure 5}

The fifth and last procedure used to compute the shear stress sets the target shear stress as the value at the crest level of the shear stress computed with the integral of the co-spectra (Figure 10). 
Tecnología y

Ciencias $₫$ Agua
2021, Instituto Mexicano de Tecnología del Agua

Open Access bajo la licencia CC BY-NC-SA 4.0

(https://creativecommons.org/licenses/by-nc-sa/4.0/)

The values of $\tau_{05}$ computed according to procedure 5 are reported in Table 7.

Table 7. Values of $\tau_{05}$ obtained with procedure 5 .

\begin{tabular}{|c|c|c|c|c|}
\hline & Test A & Test B & Test C & Test D \\
\hline & $(\mathrm{Pa})$ & $(\mathrm{Pa})$ & $(\mathrm{Pa})$ & $(\mathrm{Pa})$ \\
\hline$\tau_{05}$ & 0.38 & 1.83 & 2.23 & 1.47 \\
\hline
\end{tabular}

Figure 18 shows the scaled shear stress profile using the value of $\tau_{05}$. 


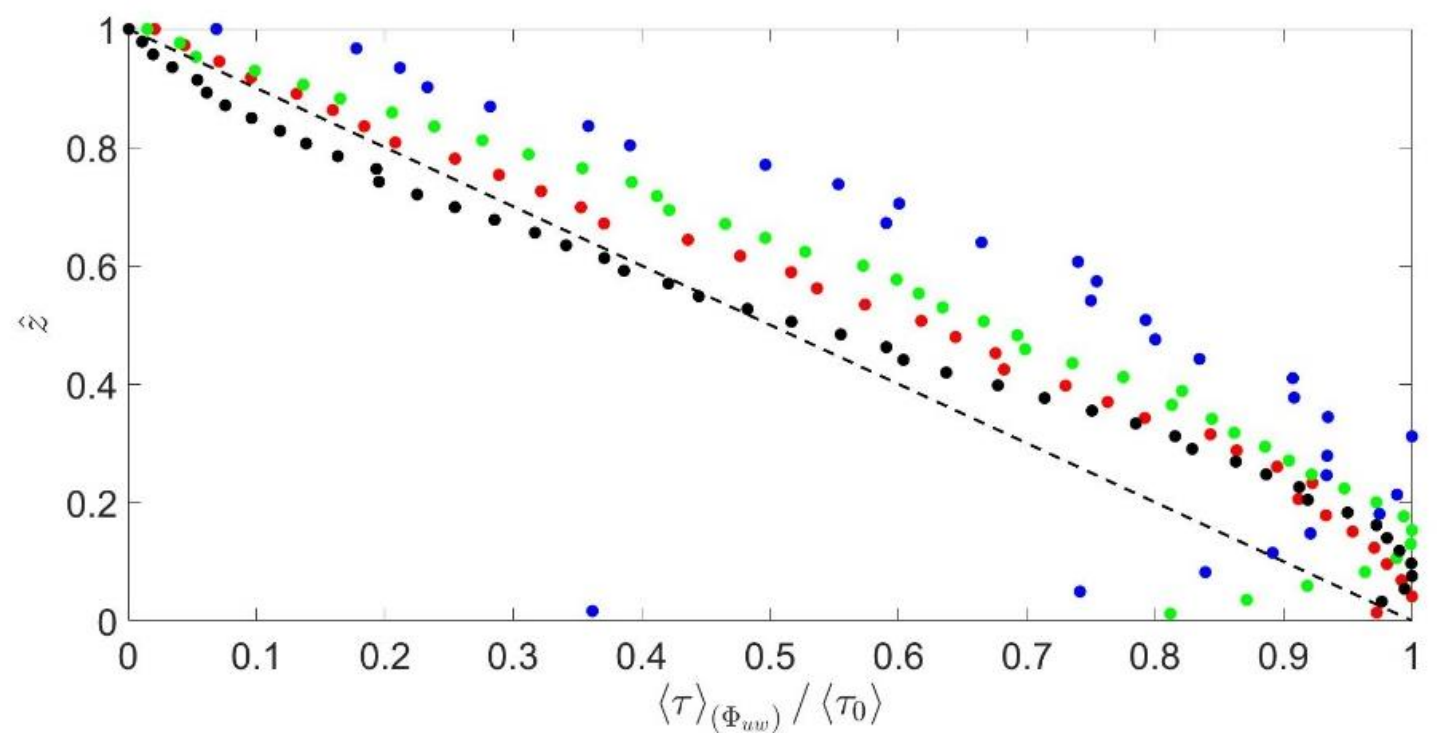

Figure 18. Non-dimensional shear stress profiles using $\tau_{05}$ computed from procedure 5 ( $\odot$ Test $A, \bullet$ Test $B, \bullet$ Test $C$ and $\bullet$ Test $D$ and --gravity line).

The large-scale shear stresses are for the majority dependent on the large scale (Guala, 2006), while there are residual components that are neglected owing to the low frequency used. For the previous method, the deviation is low and comparable with the method which shows the betterscaling (procedure 3 ). The maximum value of the large-scale shear stress is recorded at the crest level. 
Tecnología y

Ciencias $\stackrel{\unlhd}{\unlhd}$ gua
2021, Instituto Mexicano de Tecnología del Agua

Open Access bajo la licencia CC BY-NC-SA 4.0

(https://creativecommons.org/licenses/by-nc-sa/4.0/)

\section{Friction velocity}

An appropriate velocity to scale the velocity profile needs to be selected. The most used scale in literature is the $u_{*}$ that has the following form:

$u_{*}=\sqrt{\frac{\tau_{0}}{\rho_{w}}}$

where $\tau_{0}$ is the shear stress previously computed and $\rho_{w}$ is the fluid density. Table 8 is provided an overview of the velocity scales computed from Equation (14), in which the values of $\tau_{0}$ were computed from the methods previously explained.

Table 8. Velocity scale $u_{*}$ for Test A, Test B, Test C, and Test D.

\begin{tabular}{|c|c|c|c|c|}
\hline & Test A & Test B & Test C & Test D \\
\hline & $\mathrm{m} / \mathrm{s}$ & $\mathrm{m} / \mathrm{s}$ & $\mathrm{m} / \mathrm{s}$ & $\mathrm{m} / \mathrm{s}$ \\
\hline$u_{* 1}$ & 0.0274 & 0.0462 & 0.0492 & 0.0443 \\
\hline
\end{tabular}




\begin{tabular}{|c|c|c|c|c|}
\hline$u_{* 2}$ & 0.0214 & 0.0461 & 0.0447 & 0.0443 \\
\hline$u_{* 3}$ & 0.0299 & 0.0515 & 0.0522 & 0.0465 \\
\hline$u_{* 4}$ & 0.0263 & 0.0512 & 0.0503 & 0.0446 \\
\hline$u_{* 5}$ & 0.0195 & 0.0428 & 0.0472 & 0.0383 \\
\hline
\end{tabular}

Figure 19 shows the scaled velocity profiles using the values reported in Table 8 . For each method it is used the inner scaling to compare the velocity profiles. This type of scaling has in the $x$-axis the values of $\hat{z}$ and along the $y$-axis the values of $\frac{u}{u_{*}}$ referred to each procedure previously used. 
Tecnología y Ciencias $\stackrel{\unlhd}{\unlhd}$ gua
2021, Instituto Mexicano de Tecnología del Agua

Open Access bajola licencia CC BY-NC-SA 4.0

(https://creativecommons.org/licenses/by-nc-sa/4.0/)
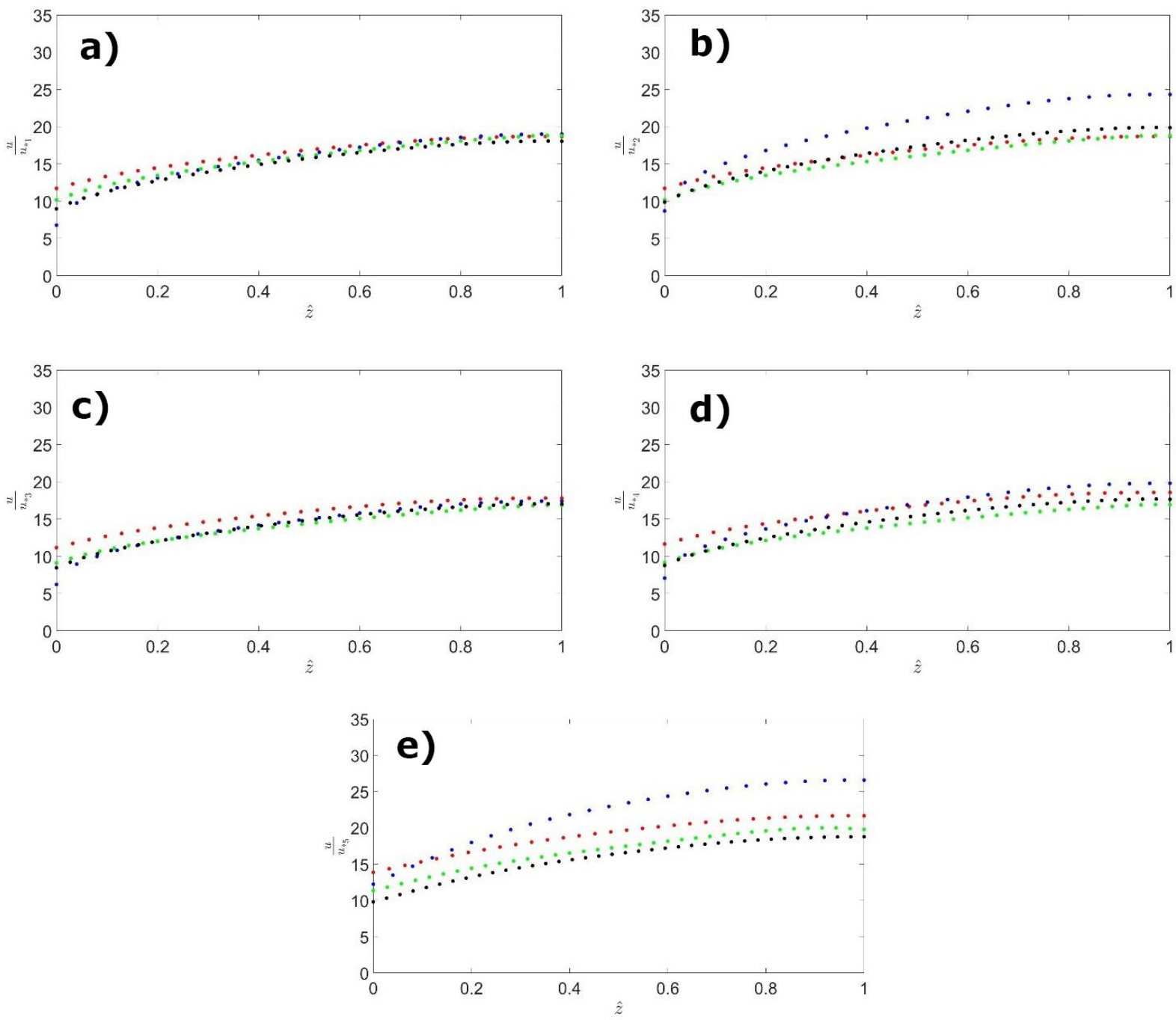

Figure 19. Inner scaling of the velocity profiles using $\mu *$ reported in Table 8 for a) procedure 1 ; b) procedure 2 ; c) procedure 3 ; d) procedure 4 , and e) procedure 5 . $\odot$ Test $A$, $\odot$ Test $B, \bullet$ Test $C$ and Test D. 
Tecnología y

Ciencias ฐAgua
2021, Instituto Mexicano de Tecnología del Agua

Open Access bajo la licencia CC BY-NC-SA 4.0

(https://creativecommons.org/licenses/by-nc-sa/4.0/)

\section{Discussion}

Figure 20 shows the comparison of the several methods used to define the best value of the scaling velocity. It is found that procedure 3, as expected, is the method which returns the best scaling for both velocity profile and shear stress profiles according to (Pokrajac, 2006). Considering the second method proposed in Graf (1995), the experimental work does not prove the effectiveness of this proposal due to the high deviation presented in the dimensionless profiles shown in Figure 19 (b). As a summary, Figure 20 reports the scaled velocity and shear stress profiles computed in accordance with procedure 3. 

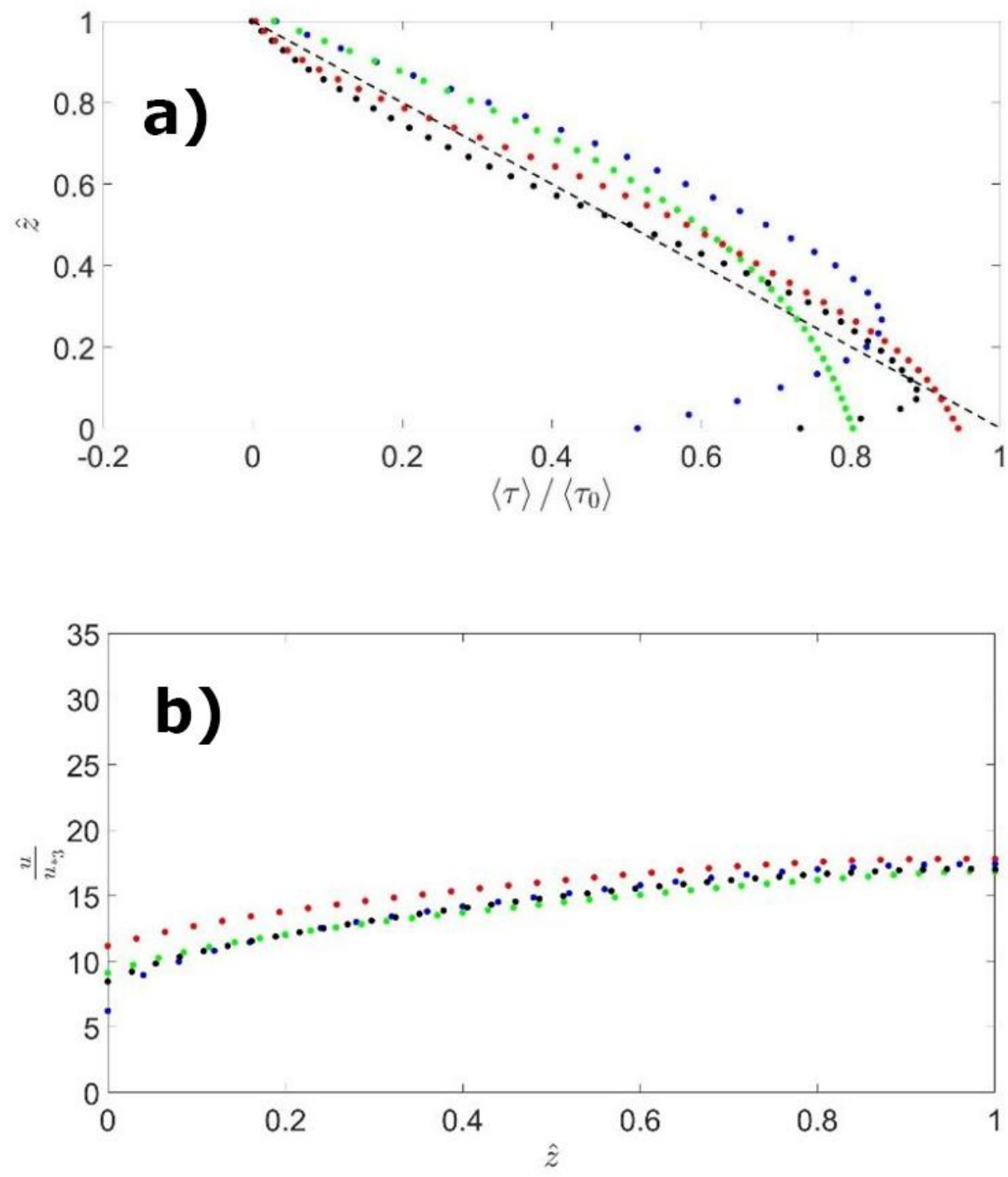

Figure 20. a) Non-dimensional shear stress; b) inner scaling of the velocity profile. $\odot$ Test $A, \bullet$ Test $B, \bullet$ Test $C$ and $\bullet$ Test $D$. 


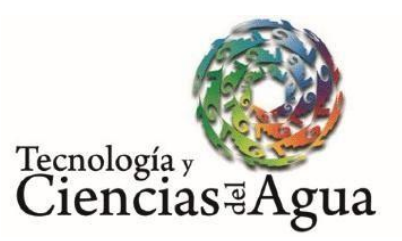

\section{Conclusions}

This work was focused on the definition of the best velocity scale in OCFs over a live bed.

Four experiments were performed to check the solid transport influence on the bed shear stress as well as the shear velocity. Several methods in the literature for the definition of the shear stress and shear velocity are based on the assumption of steady and uniform flow conditions and universal log-law existence. In this work, these conditions have been removed and direct measurement methods have been employed to find the shear stress and the shear velocity.

After the preliminary analysis, several methods to find the bed shear stress and shear velocity were proposed. Shear velocity is widely used as a universal velocity, often in the context of the log-law, but also for scaling the data in open channel flows with bed transport where the log-layer is not present (Katul, 2002).

Namely, procedure 1 is devoted to finding the maximum of the shear stress profile, procedure 2 to identify the value at the crest level of the shear stress profile, procedure 3 to consider the value at the crest level extrapolated from a linear fit of the shear stress profile, procedure 
4 to obtain the value at a negligible form-induced shear stress of a linear fit of the shear stress profile and procedure 5 to find the maximum value of the large scale shear stress computed as integral of the co-spectra.

The bed shear stress which gives the best scaling has been found in procedure 3 (Figure 20). All the bed shear stresses were also used to find the shear velocity as a scaling parameter, confirming that the best procedure is number 3 .

PIV technique due to its high spatial resolution could be applied, in future works, using the procedure applied in Ferraro (2019), adapting this method based on an Acoustic Doppler Velocimeter system to a PIV system.

\section{References}

Adrian, R. J. (1986). Multi-point optical measurements of simultaneous vectors in unsteady flow-a review. International Journal of Heat and Fluid Flow, 7(2), 127-145.

Adrian, R. J. (1991). Particle-imaging techniques for experimental fluid mechanics. Annual review of fluid mechanics, 23(1), 261304. Recovered from https://doi.org/10.1146/annurev.fl.23.010191.001401.

Dynamics, D. (2013). DynamicStudio User's Guide. Skovlunde, Denmark: Dantec Dynamics. 

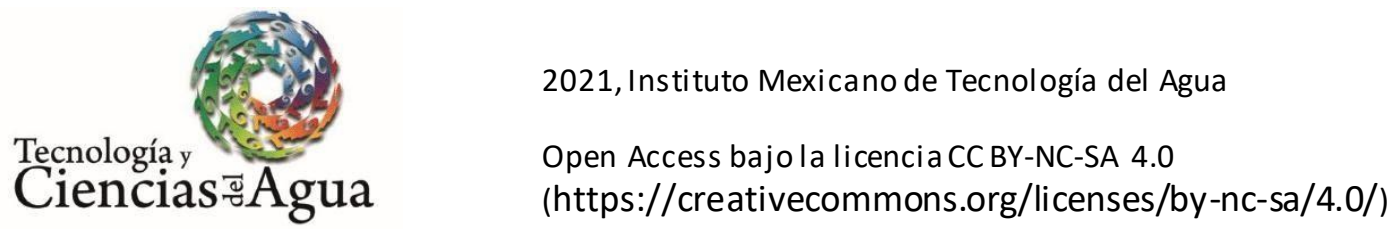

Ferraro, D. S. (2019). Velocity scales in steady-nonuniform turbulent flows with low relative submergence. Environmental Fluid Mechanics, 19(4), 1025-1041.

Ferreira, R. M. (2011). Turbulent flow hydrodynamics and sediment transport: Laboratory research with LDA and PIV. In: Experimental methods in hydraulic research (pp. 67-111). Berlin7 Heidelberg, Germany: Springer.

Giménez-Curto, L. A. (1996). Oscillating turbulent flow over very rough surfaces. Journal of Geophysical Research: Oceans, 101(C9), 20745-20758.

Graf, W. H. (1995). Bed-shear stress in non-uniform and unsteady open-channel flows. Journal of Hydraulic Research, 33(5), 699704.

Guala, M. H. (2006). Large-scale and very-large-scale motions in turbulent pipe flow. Journal of Fluid Mechanics, 554, 521-542. DOI:10.1017/S0022112006008871

Katul, G. W. (2002). A mixing layer theory for flow resistance in shallow streams. Water Resources Research, 38(11), 32-41. Recovered from https://doi.org/10.1029/2001WR000817.

Liu, J., \& Iskander, M. (2004). Adaptive Cross-Correlation for Imaging Displacements in Soils. Journal of Computing in Civil Engineering, 18(1), 46-57. 


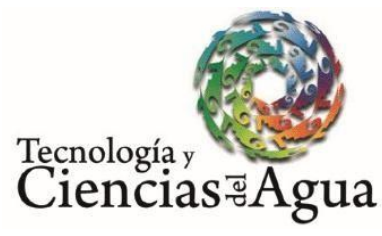

2021, Instituto Mexicano de Tecnología del Agua

Open Access bajo la licencia CC BY-NC-SA 4.0

(https://creativecommons.org/licenses/by-nc-sa/4.0/)

Nikora, V. G. (2001). Spatially averaged open-channel. Journal of Hydraulic Engineering, 127(2), 123-133.

Pokrajac, D. F. (2006). On the definition of the shear velocity in rough bed open channel flows. In: Procedures of the International Conference on Fluvial Hydraulics, vol. 1 (pp. 89-98)., London, England.

Pokrajac, D. M. (2008). Spatially averaged turbulent stress and its partitioning. Experiments in Fluids, 45(1), 73-83.

Raffel, M. W. (2007). Particle image velocimetry: A practical guide. Springer Science \& Business Media, 3. Recovered from https://doi.org/10.1007/978-3-319-68852-7.

Reynolds, O. (1895). IV. On the dynamical theory of incompressible viscous fluids and the determination of the criterion. Philosophical Transactions of the Royal Society of London A, Mathematical and Physical Sciences, 186, 123-164.

Stewart, M. T. (2014). Turbulence structure of rough-bed open-channel flow (Ph.D. thesis). University of Aberdeen, Aberdeen, United Kingdom.

Whitaker, S. (1967). Diffusion and dispersion in porous media. AIChE Journal, 13(3), 420-427. Recovered from https://doi.org/10.1002/aic.690130308 
Tecnología y

Ciencias $\cong$ Agua
2021, Instituto Mexicano de Tecnología del Agua

Open Access bajola licencia CC BY-NC-SA 4.0

(https://creativecommons.org/licenses/by-nc-sa/4.0/)

Wilson, N. R. (1977). A higher-order closure model for canopy flow. Journal of Applied Meteorology, 16(11), 1197-1205. Recovered from https://doi.org/10.1175/15200450(1977)016<1197:AHOCMF>2.0.CO;2

Zagni, A. F. (1976). Channel flow over permeable beds of graded spheres. Journal of the Hydraulics Division,102(2), 207-222. 